\title{
A novel method of sensitivity analysis testing by applying the DRASTIC and fuzzy optimization methods to assess groundwater vulnerability to pollution: the case of the Senegal River basin in Mali
}

\author{
Keita Souleymane $^{1,2}$ and Tang Zhonghua ${ }^{1}$ \\ ${ }^{1}$ Department of Hydrology and Water Resources, School of Environmental Studies of China University \\ of Geosciences, Lumo Road, Wuhan 430074, China \\ ${ }^{2}$ Department of Civil Engineering, ENI-ABT, 410, Av. Van Vollenhoven P.O. Box, 242 Bamako, Mali \\ Correspondence to: Keita Souleymane (soulkei_ml@yahoo.fr)
}

Received: 27 March 2017 - Discussion started: 3 April 2017

Accepted: 4 July 2017 - Published: 9 August 2017

\begin{abstract}
Vulnerability to groundwater pollution in the Senegal River basin was studied by two different but complementary methods: the DRASTIC method (which evaluates the intrinsic vulnerability) and the fuzzy method (which assesses the specific vulnerability by taking into account the continuity of the parameters). The validation of this application has been tested by comparing the connection in groundwater and distribution of different established classes of vulnerabilities as well as the nitrate distribution in the study area. Three vulnerability classes (low, medium and high) have been identified by both the DRASTIC method and the fuzzy method (between which the normalized model was used). An integrated analysis reveals that high classes with $14.64 \%$ (for the DRASTIC method), $21.68 \%$ (for the normalized DRASTIC method) and $18.92 \%$ (for the fuzzy method) are not the most dominant. In addition, a new method for sensitivity analysis was used to identify (and confirm) the main parameters which impact the vulnerability to pollution with fuzzy membership. The results showed that the vadose zone is the main parameter which impacts groundwater vulnerability to pollution while net recharge contributes least to pollution in the study area. It was also found that the fuzzy method better assesses the vulnerability to pollution with a coincidence rate of $81.13 \%$ versus that of $77.35 \%$ for the DRASTIC method. These results serve as a guide for policymakers to identify areas sensitive to pollution before such sites are used for socioeconomic infrastructures.
\end{abstract}

\section{Introduction}

A key component to building a territory is the vulnerability map, which is a fundamental water quality assessment that aids the development of underground water resources. Among the myriad of functions delivered by a geographic information system (GIS), its capability for multi-criteria analysis is essential for developing vulnerability maps for an aquifer system. Water quality information is a basic data requirement for implementing any water management decision. It provides necessary information for assessing risk of groundwater pollution and remediation measures needed to control future pollution levels. This information can be retrieved from groundwater pollution vulnerability maps. To assess the vulnerability of groundwater to pollution, 24 methods exist, which can be classified into three groups.

- Comparison methods are used mainly for very large study areas and take into consideration two to three parameters.

- Methods of analog relationship and numerical models are based on simple or complex mathematical laws and are recommended for assessing the vulnerability of radioactive sites.

- Parametric systems are composed of three subsystems:

- The matrix system, adapted for local use, is based on a limited number of judiciously chosen parameters. The procedure is a combination of classes that define descriptively the vulnerability of aquifers. 
- The class system defines a range for each parameter considered necessary for assessing vulnerability, then subdivides each of the intervals selected based on the variability of the parameter. The final score resulting from the summation (or multiplication) of each score for the different parameters should be divided by the number of classes chosen.

- The weighted class system is based on assigning ratings to the parameters, which are retained as necessary for the evaluation of groundwater vulnerability by defining intervals, as is the case with other methods cited previously. Subsequently a weight is applied for each parameter according to its importance to the assessment of vulnerability.

Water is one of the most essential parts of our daily life. Water management is becoming increasingly problematic due to, for example, climate, pollution and environmental issues. Surface water and groundwater are often polluted. Since the water system is a cycle, water in the air, water on land and water underground are all connected. Groundwater and surface water are connected through a very complicated hydrogeological system that can lead to mutual contamination, which means that if groundwater is polluted it can affect the upper surface water and if surface water is polluted it can affect the underlying groundwater.

Sustainable management of Senegal River basin resources is a major issue for the four riparian countries of Guinea, Mali, Mauritania and Senegal.

The multiple uses of water and the multinational nature of the basin led the riparian countries to create the Organization for the Development of the Senegal River (OMVS in French) to manage the basin's water resources. For this, each country needs data and information enabling it to monitor and predict the evolution of the resources, in particular in light of the importance of climate variability in the region marked by the recurrence of drought, the potential impacts of climate change and the increasing impacts of population on water resources. Many other water uses in the basin also require data and information for their activities.

The Senegal River basin in Mali is increasingly dominated by cultures and industries that use chemicals. This strong demand for chemicals threatens the quality of groundwater resources. Groundwater reserves are substantial and are being used to cover different needs. They are also used as a source of drinking water in the region, which is experiencing rapid population growth at a rate of $3 \%$ per year (O.M.V.S., 2013). The quality of this groundwater resource is constantly put to the test because of the growth of both point and diffuse pollution sources. To prevent the risk of pollution of groundwater, a modified approach is the gathering of knowledge about areas vulnerable to pollution. Civita (1994) showed that aquifer groundwater's changes (in quality and quantity) in time and space are due to natural processes and/or human activities.
Work already done in the area (Newton, 2007; UNESCO, 2012) mainly concerns the quantity of water resource management. Other studies (Anoh, 2009; Jourda et al., 2007) have focused on the quality of water resources but they did not focus on the same area nor did they find vulnerability zones.

However, none of these studies have investigated the impact of human and natural activities on groundwater resources in the basin of the Senegal River in Mali. Thus, the present study uses fuzzy and DRASTIC methods to evaluate the intrinsic and specific vulnerability to pollution to highlight those impacts. The intrinsic vulnerability method is inflexible because its weights and ratings are fixed according to hydrogeological parameters, while the specific vulnerability method is flexible and takes into account local hydrogeological conditions and continuity of parameters (Afshar et al., 2007; Antonakos et al., 2007; Alemi-Ardakani et al., 2016; Madhumita et al., 2016).

The DRASTIC method is the most common method to assess groundwater vulnerability to pollution (Denny et al., 2007; Bojórquez-Tapia et al., 2009; Dhar et al., 2014). However, this method is increasingly criticized for the choice of hydrogeological features; the weights and the ratings do not necessarily agree with the reality of the study area and its specificity (Denny et al., 2007; Dhar et al., 2013; Madhumita et al., 2016). So to improve and adapt the DRASTIC model to the particularity of the study area, it is better to modify the classical model or combine it with other developed models to get better results. Many studies proposed methods which combined DRASTIC and other methods (Yu et al., 2012; Dhar and Patil, 2012; Fernando et al., 2013; Madhumita et al., 2016). Leone et al. (2009), Luis et al. (2009) and Neshat et al. (2015a, b) all proposed modified models to assess groundwater vulnerability to pollution. However, none of them focused on a comparison between classical sensitivity analyses (single parameter and map removal) and fuzzy membership. The DRASTIC method is essentially based on subjective setting of study area hydrogeological conditions (Nobre et al., 2007; Madhumita et al., 2016) while the fuzzy concept is based on membership, which is an objective setting of study area hydrogeological conditions (Pacheco et al., 2015; Madhumita et al., 2016). For example, membership expresses the relations between two given parameters and also the degree of truth or falseness of these relations (Pacheco et al., 2015; Madhumita et al., 2016). This technique has been used by many authors - such as Pacheco et al. (2015), Madhumita et al. (2016), Pathak et al. (2009), Sahoo et al. (2016a, b), Saidi et al. (2011) and Sener et al. (2013) - but most of these studies assessed pollution risk (Pacheco and Van der Weijden, 2011, 2012) and did not compare intrinsic with specific vulnerability or different types of sensitivity analyses with memberships to identify parameter impact on groundwater vulnerability to pollution.

The aim of our study is to find useful and relevant information to guide policy choices for prevention and management 
of risks of pollution of groundwater resources in this area through sustainable management.

The DRASTIC method uses weighted classes and was developed by the US Environmental Protection Agency (EPA) and the National Water Well Association (NWWA) in 1987 to evaluate the vulnerability of groundwater to pollution. Although it was not originally designed for GIS, it is a classic spatial analysis widely used in GIS.

The objective of DRASTIC is to give a standard methodology that gives reliable results useful for efforts to protect groundwater.

DRASTIC generates an index, or "score", for the potential pollution of groundwater resources. This index covers the entire range from 23 to 226 . Note that the vulnerability to pollution is higher for higher notes.

The DRASTIC method uses seven hydrological parameters: the depth of the water level of the water table (D), the net recharge $(\mathrm{R})$, the lithology of the aquifer (A), the soil texture $(\mathrm{S})$, the topography slope of the field $(\mathrm{T})$, the impact of the unsaturated zone (I) and, finally, the hydraulic conductivity or permeability of the saturated zone (C).

In GIS, each parameter is scored on a layer by assigning a weight coefficient corresponding to the parameter, i.e., its influence on the vulnerability of the aquifer. Then these layers are superimposed on a layer for which results will be calculated as the DRASTIC pollution index (DPI). The layers will have the same cartographic features - a single projection system, identical units of length, identical geographical area and the same resolution - because this system uses a matrix format for all calculations.

DPI is dimensionless. The number or the order of magnitude has no meaning in itself. The unity of the DPI occurs when comparing two sites or one site to several other sites. The site with the highest DPI will be considered most susceptible to contamination or pollution.

More than 24 vulnerability assessment methods of groundwater to pollution are identified in the literature. The method most often used is the DRASTIC method. It was developed by Aller et al. (1987) and is an assessment method (vulnerability aquifers) based on weights and ratings for different parameters (generally between 1 and 10). A weight is also allocated according to the relative importance of each of the parameters used. The DRASTIC numerical rating system incorporates seven different physical parameters involved in the transportation process and mitigation of contaminants: water depth, effective recharge, aquifer and soil type, topography, impact of unsaturated zone and hydraulic conductivity. In the first step, a numerical value ranging from 1 to 5 is allocated to each of the seven parameters, topography, vadose zone and hydraulic conductivity of aquifer media. Each of these parameters is a weight (predetermined value), between 1 and 5, that reflects the importance of the parameter in the transport processes and contaminant attenuation. A key parameter is assigned a weight of 5 while a setting with less impact on the fate of a contaminant is assigned a weight of 1 . In the second step, each of the seven parameters is assigned a value ranging from 1 to 10 , defined in terms of ranges of values. The smallest value represents lower vulnerability to contamination ( $D_{\mathrm{c}}, R_{\mathrm{c}}, A_{\mathrm{c}}$, etc.). For each hydrogeological unit, the seven parameters must then be evaluated to give each a rating that can vary from 1 to 10 . A rating of 1 corresponds to the lowest vulnerability while a rating of 10 reflects the conditions most likely to be contaminated. DRASTIC's parameters were reclassified in ArcMap and assigned a score based on rankings ranging from 1 to 10 and a weighting to help merge factors together in the DRASTIC equation in GIS. Each of the seven parameters was then assigned a multiplicative factor $(w)$ ranging from a value of 5 for the most significant factors to 1 for factors that are less so.

The DPI was determined according to Eq. (1) as in Osborn et al. (1998), where $D, R, A, S, T, I$ and $C$ are the seven parameters of the DRASTIC method, $w$ is the weight of the parameter and $r$ the associated rating. The weights of the parameters of the DRASTIC method used (Table 1) are those defined by Aller et al. (1987). The reference values of the index used in DRASTIC are those provided by Engel et al. (1996) and represent the measurement of the hydrogeological aquifer vulnerability.

$$
\begin{aligned}
\mathrm{DPI} & =D_{r} D_{w}+R_{r} R_{w}+A_{r} A_{w} \\
& +S_{r} S_{w}+T_{r} T_{w}+I_{r} I_{w}+C_{r} C_{w}
\end{aligned}
$$

or

$\mathrm{DPI}=\sum_{k=1}^{7} r_{k} w_{k}$,

where $r$ is the rating ( 1 to 10$), w$ is the weight ( 1 to 5 ) and $k$ is the parameter (1 to 7 ).

In the final step, the calculation of the DRASTIC index for each hydrogeological unit is obtained by multiplying the rating of each parameter by it corresponding weight. DPI represents the level of risk of the aquifer unit to be contaminated. It can reach a maximum of $226(100 \%)$ and a minimum value of $23(0 \%)$.

\section{Materials and methods}

The Senegal River basin is among the largest rivers in West Africa. The territory of its basin is bounded by parallels $10^{\circ} 30^{\prime}$ and $17^{\circ} 30^{\circ} \mathrm{N}$ and meridians $7^{\circ} 30^{\prime}$ and $16^{\circ} 30^{\circ} \mathrm{W}$. The Senegal River ranks seventh in terms of basin area and runoff among African rivers and second in West Africa after the Niger River. The Senegal River basin, located in West Africa, covers $1.6 \%$ of the continent and spreads over four countries (Guinea, Mali, Mauritania and Senegal). The Senegal River is formed by the confluence of two smaller rivers, the Bafing and Bakoye, which occurs near Bafoulabé, Mali, about $1083 \mathrm{~km}$ from the Atlantic Ocean. After crossing western Mali, the Senegal River constitutes the boundary between Senegal and Mauritania. The Senegal River basin occupies a 
total area of $289000 \mathrm{~km}^{2}$. Along $760 \mathrm{~km}$, Bafing rises at an altitude of $800 \mathrm{~m}$ in the Fouta Djallon in Guinea and flows north across the plates of the Sudanese region before reaching Bafoulabé. It brings more than half of the total flow of the Senegal River with $430 \mathrm{~m}^{3} \mathrm{~s}^{-1}$ mean annual flow. The river is characterized by the presence of falls and rapids. With a length of $560 \mathrm{~km}$, Bakoye's source is near the southern boundary of Mandingo Mountain in Guinea, at an altitude of $706 \mathrm{~m}$. At its confluence with Bafing, Bakoye has a mean annual flow of $170 \mathrm{~m}^{3} \mathrm{~s}^{-1}$. This river also passes a relatively large number of small waterfalls and rapids. Bafoulabé is located downstream on the right bank; the main tributaries of the Senegal River are Kolombiné, Karakoro and Gorgol. On the left bank, Falémé River is the largest tributary at $650 \mathrm{~km}$ long; it rises in the northern part of Fouta Djallon, at an altitude of $800 \mathrm{~m}$. It joins the Senegal River $30 \mathrm{~km}$ upstream from Bakel. The annual flow at its outlet in the Senegal River is about $200 \mathrm{~m}^{3} \mathrm{~s}^{-1}$.

With a length of $1800 \mathrm{~km}$, Senegal River starts in northern Guinea, crosses the western part of Mali and remains the borderline between the territories of the Republic of Senegal and the Islamic Republic of Mauritania.

There are two main parts:

- the Senegal upper basin is located upstream of Bakel, a mountainous region, and is made up of the basins of the Falémé, the Bafing, the Bakoye and Baoulé rivers;

- the Senegal lower basin is located downstream of Bakel in a very flat, slightly accentuated area, where the maximum does not exceed $400 \mathrm{~m}$ (Massif Assaba) and where the river flows in the middle of a very wide valley;

- the watershed of the river covers a total area of $289000 \mathrm{~km}^{2}$ with $155000 \mathrm{~km}^{2}$ in Mali (upper basin), spread between Kayes (Kéniéba, Bafoulabé, Kita, Kayes, Diéma, Yélimané and Nioro) and Koulikoro (Banamba, Kolokani and Nara).

Our study concerns the upper Senegal basin (Fig. 1a), which is situated in Mali.

The working material consists of multiple data sources. This includes piezometric data from filed measurements of groundwater level collected in different years in the region and complemented by the database "sigma" of the National Water Directorate (DNH). Drilling data sheets were provided by various campaigns monitoring the supply of drinking water; also, the National Water Laboratory (LNE) allowed the use of drilling depth data, groundwater levels, lithological cuts and pumping test. These data helped create several vulnerability maps. To these data we added geological maps of the region and the soil sketch of Mali provided by the FAO.

Finally, the coordinates of the Shuttle Radar Topography Mission (SRTM) (http://srtm.csi.cgiar.org) were used for the land use and land cover images of the study area. This image treatment was used to establish a digital elevation model
(DEM) with a resolution of $90 \mathrm{~m}$ and highlights the slope map.

The processing of these data is performed on ArcGIS 10.0 for cartographic processing, processing of satellite images and generating the slope map and the combination of other thematic maps.

For this study we used two different methods: one to assess the intrinsic vulnerability (DRASTIC) and the second to find the specific vulnerability (fuzzy).

The DRASTIC method is a method for mapping the inherent vulnerability of aquifers.

This method has already been the subject of several applications in the literature. Mohamed (2001) evaluated aquifer vulnerability to pollution in El Madher (Algeria); Murat et al. (2003) assessed the southwestern aquifer pollution in Québec (Canada); Jourda et al. (2006) and Kouame et al. (2007) also used the DRASTIC method to assess the vulnerability to pollution of, respectively, Korhogo (northern Ivory Coast) and Bonoua (southern Ivory Coast) aquifers. Although sometimes modified (Hamza et al., 2007), it remains effective as a vulnerability assessment tool. To test this ability it has been added to the fuzzy method, which is one of these variants.

The joint application of the two methods has the advantage of ensuring complementarity in evaluating the vulnerability of groundwater to pollution. These methods are in the form of a numeric rating system, based on the consideration of various factors influencing the hydrogeological system. In the assessment of the vulnerability process, the seven parameters of interest used in both methods include the depth of the water level, the effective recharge of the aquifer, soil types, topography, impact of vadose zone or the effect of selfpurification of the vadose zone, the lithology of the aquifer and the hydraulic conductivity of the aquifer.

The DRASTIC method uses formulas that test the linear relationship between the parameters, while the fuzzy method uses formulas that take into account the continuity of pollution from one point to another.

\subsection{Vulnerability assessment by the DRASTIC method}

Polygon maps were initially generated for all seven DRASTIC maps by georeferencing, digitizing and editing.

These polygon maps were classified according to their importance for aquifer pollution potential (a value from 0 to 10 was assigned to each map). So for each parameter we created specific polygon maps by adding these ratings to an attribute table in GIS. Specific polygon maps were then converted into raster maps according to their ratings. We assigned weight to these raster maps and combined them to get the final vulnerability map by using Eq. 1 or 2 .

The DRASTIC method is frequently used to study groundwater vulnerability (Shirazi et al., 2013; Sinha et al., 2016). In the United States, Hearne et al. (1992), Merchant (1994) 

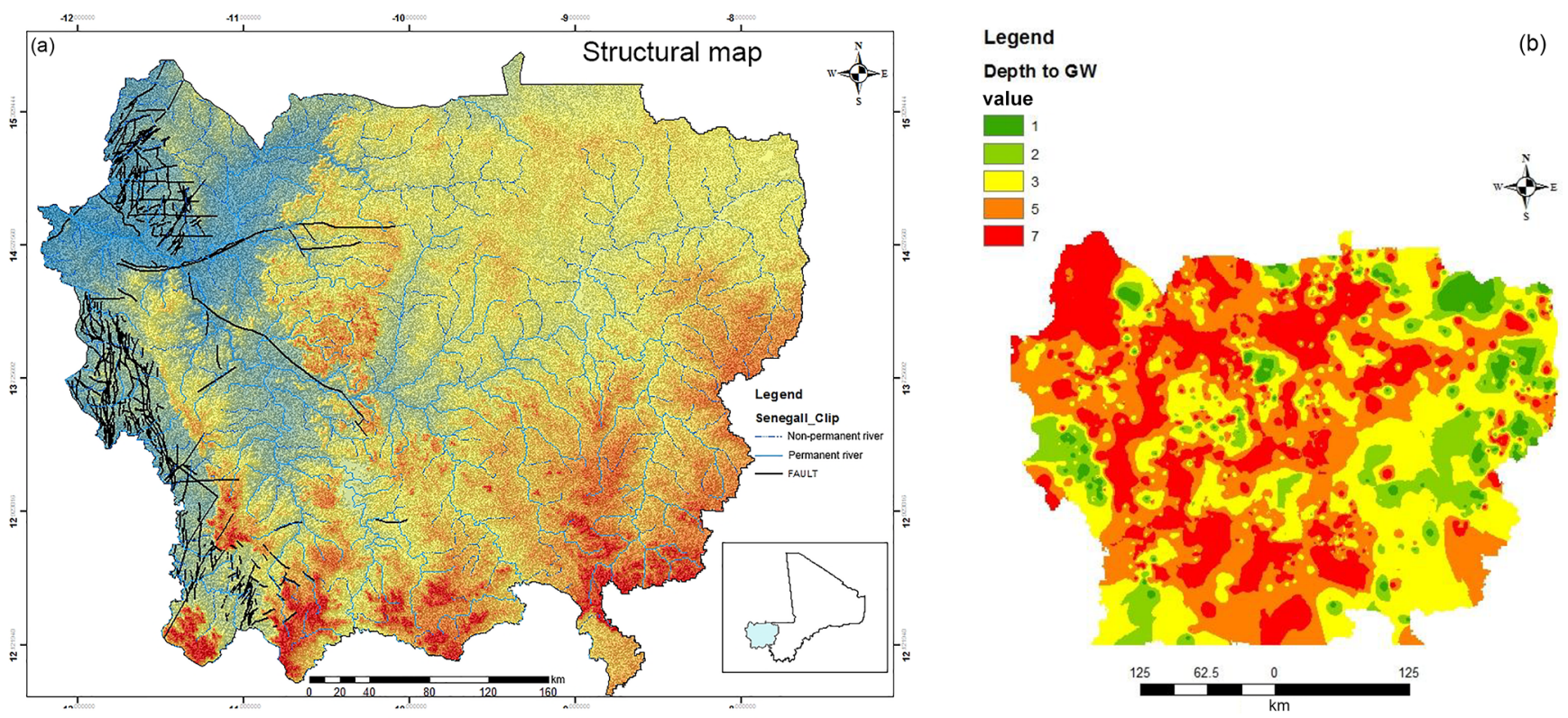

Figure 1. (a) Study area location and hydrogeological map. (b) Groundwater (GW) depth distribution map.

and Atkinson (1994); Kalinski (1994) used this method to assess groundwater vulnerability.

The DRASTIC model has already been used in other countries worldwide. It was used for the assessment of groundwater pollution in Anekal Taluk, a semi-arid area in the district of Bangalore (Chandrashekhar et al., 1999).

Jha et al. (2005) used the DRASTIC method to assess groundwater vulnerability in Ranchi, Jharkhand.

To assess DRASTIC parameters we need to identify and study all hydrogeological and meteorological conditions of the study area (Anwar et al., 2003; Hamza, 2006)

The following parameters were used for the DRASTIC method.

\subsubsection{Groundwater table depth}

Groundwater table depth is the distance between the uppermost layer of unsaturated zone and groundwater static level. It controls the thickness and amount of possible contaminants (Ckakraborty, 2007). Therefore when this distance is high, it is more difficult for surface water to cross (under chemical and biological reactions) this layer and to reach groundwater.

We use water table depth data from borehole data collected by national directorates in charge of water resources management in Mali.

These data show that the depth varies from $1.50 \mathrm{~m}$ to more than $120 \mathrm{~m}$. As in Dhundi et al. (2009), for depth beyond $100 \mathrm{~m}$ we assigned a rating of 0 because it is almost impossible for pollutants to reach groundwater due to processes like sorption, filtration, biodegradation and volatilization. Table 1
Table 1. Range and rating for depth of water.

\begin{tabular}{lrr}
\hline Range $(\mathrm{m})$ & Rating & Index \\
\hline$\leq 1.5$ & 10 & 50 \\
$1.6-4.6$ & 9 & 45 \\
$4.6-9.1$ & 7 & 35 \\
$9.1-15.2$ & 5 & 25 \\
$15.2-22.5$ & 3 & 15 \\
$22.5-30$ & 2 & 10 \\
$\geq 30$ & 1 & 5 \\
\hline
\end{tabular}

Weight: 5

shows all the values for weight and scores for groundwater static level depth, and maps of the area are shown in Fig. 1.

To generate the map we used the inverse distance moving average to get good accuracy (Samake et al., 2010, 2011). We assigned sensitivity rating values as in Dhundi et al. (2009): for $D<1.5 \mathrm{~m}$ we assigned a rating of $r=10$; if $1.5 \mathrm{~m}<D<4.6 \mathrm{~m}$ then $r=9$; if $4.6 \mathrm{~m}<D<9.1 \mathrm{~m}$ then $r=7 ; 9.1 \mathrm{~m}<D<15.2 \mathrm{~m}$ then $r=5 ; 15.2 \mathrm{~m}<D<22.5 \mathrm{~m}$ then $r=3$; if $22.5 \mathrm{~m}<D<30 \mathrm{~m}$ then $r=2$ and if $D>30 \mathrm{~m}$ and the region has no data we assigned the rating value $r=1$.

\subsubsection{Recharge}

The yearly mean quantity of water that penetrates the unsaturated zone and touches the groundwater (Aller et al., 1987), groundwater recharge or net recharge is the water that flows from ground surface to groundwater. It can easily bring contaminants into groundwater. Thus, the recharge value increases with aquifer vulnerability potential because disper- 
Table 2. Range and rating for net recharge.

\begin{tabular}{lrr}
\hline Range $\left(\mathrm{mm} \mathrm{year}^{-1}\right)$ & Rating & Index \\
\hline $20-50$ & 1 & 3 \\
$50-100$ & 3 & 9 \\
$100-300$ & 6 & 18 \\
\hline
\end{tabular}

Weight: 3

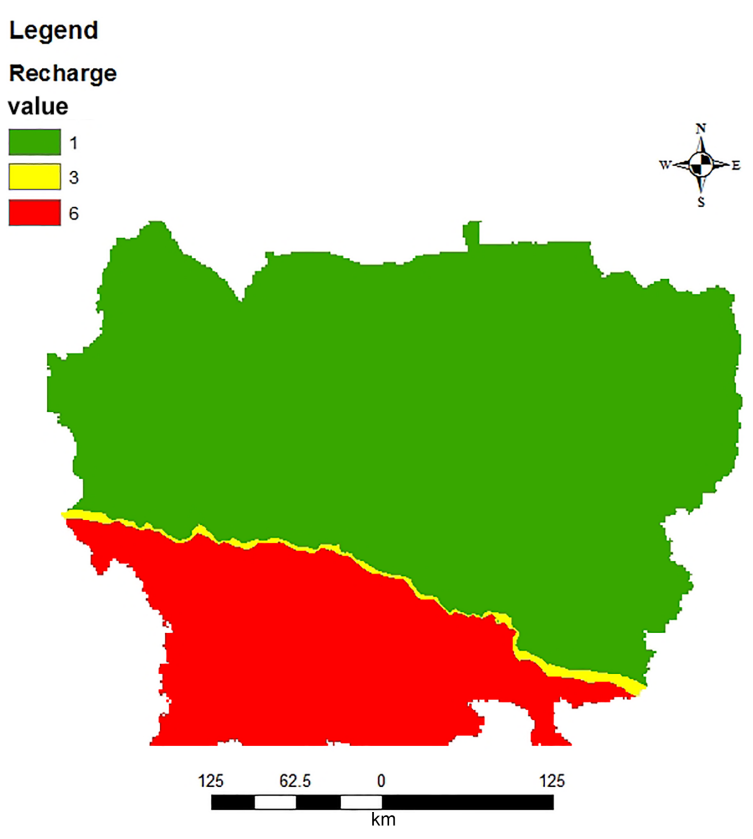

Figure 2. Groundwater recharge distribution map.

sion, dilution, etc. will increase in unsaturated zones also. There are many sources of recharge in the study area, including precipitation, irrigation, waste water, return flow and infiltration from surface water (rivers, springs, etc.).

Net recharge data were taken from a report on the hydrogeological synthesis of Mali (Mali Groundwater Resource Investigation, 1990). The different values of net recharge are in Table 2. Figure 2 represents the recharge map.

We used the following formula to calculate net recharge: net recharge $=($ rainfall - evaporation $) \times$ recharge rate .

\subsubsection{Aquifer media}

Aquifer media has been previously defined by many researchers: it describes rocks (consolidated and unconsolidated) which are used as water storage (Chandrashekhar et al., 1999). According to Heath (1987) an aquifer is an underground rock or deposit unit that will produce enough water to a borehole. The aquifer is also designated as a geological or hydrogeological formation which can produce enough water for consumption (Anwar et al., 2003). It is very important for attenuating pollution because it is the media where all reactions take place, and grain size and sorting are very important
Table 3. Range and rating for aquifer media.

\begin{tabular}{lrr}
\hline Range & Rating & Index \\
\hline Silty sand & 3 & 9 \\
Fine sand & 4 & 12 \\
Medium sand & 6 & 18 \\
Coarse sand & 8 & 24 \\
Gravel and sand & 9 & 27 \\
Gravel & 10 & 30 \\
\hline
\end{tabular}

Weight: 3

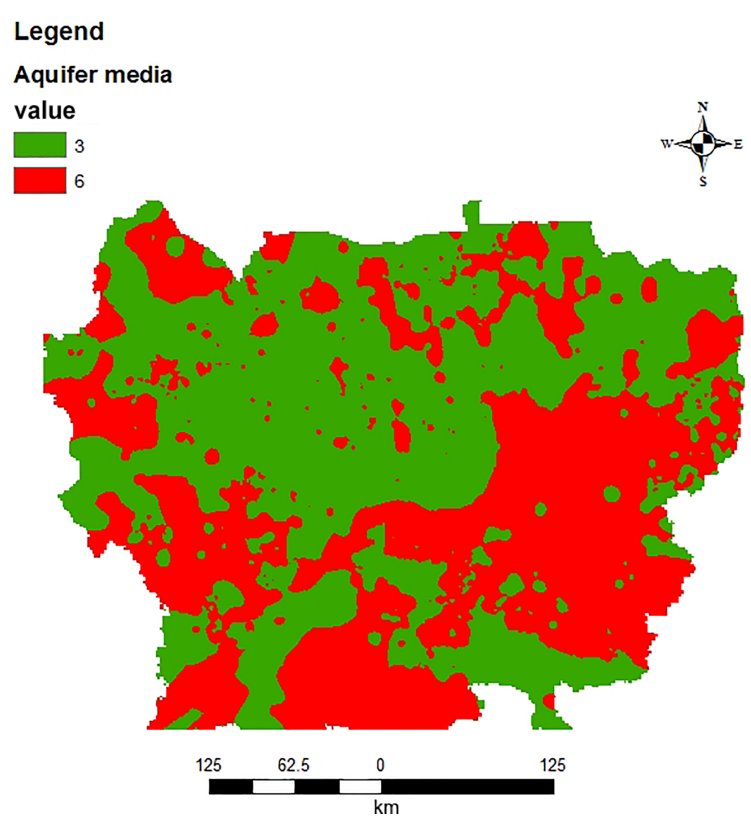

Figure 3. Aquifer media distribution map.

in pollutant attenuation. Also the aquifer media governs flow path and length in an aquifer. Hence Piscopo (2001) indicates that the duration of time available for attenuation is determined by the path length. In this study, we used topographical map and well log data to prepare the aquifer media map. We assigned high rating values to coarse media and low values to finer media. With the Mali hydrogeological synthesis maps and report on Senegal River basin groundwater simulations, the aquifer media data (Table 3 ) for this research were computed (Fig. 3) from more than 2300 boreholes.

\subsubsection{Soil media}

Soil media is the ground surface of the vadose zone. The quantity and shrink/swell capacity of clay in soil, soil grain type, sorting and size are both important because they influence groundwater movement, potential dispersion, pollutants migration throughout biological and physico-chemical reactions (sorption, biodegradation, ionic exchange, oxidation, reduction, etc.). 
Table 4. Range and rating for soil media.

\begin{tabular}{lrr}
\hline Range & Rating & Index \\
\hline Gravel & 10 & 20 \\
Sand & 9 & 18 \\
Sandy loam & 6 & 12 \\
Loam & 5 & 10 \\
Silty loam & 4 & 8 \\
Clay loam & 3 & 6 \\
\hline
\end{tabular}

Weight: 2

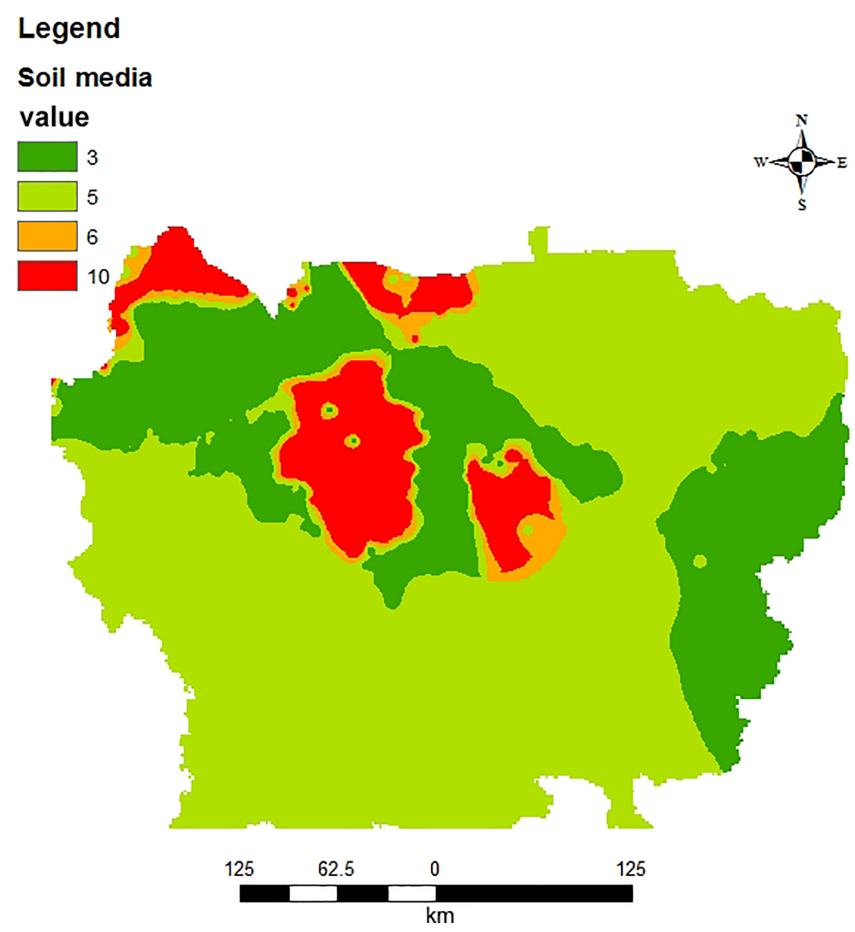

Figure 4. Soil type distribution map.

The permeability of the soil media was used as a basis for assigning ratings on a scale of 1 to 10 . The coarsest soils were assigned a rating of 10 and this decreased all the way to the finest media, which were assigned a rating of 1 . Details of rating and index are shown on Table 4, while the soil map is shown in Fig. 4.

\subsubsection{Topography}

Topography of an area accounts for the change in slope. It is a determining factor of how rainfall and pollutants will either overflow or infiltrate (Lynch et al., 1994). The longer the water and/or pollutant is retained in an area, the greater the chance for infiltration is and, consequently, the higher the potential for recharge. Gentler slopes (slopes of 0-2\%) have higher retaining capacity for water and/or pollutants while steeper slopes (slopes of $+18 \%$ ) have lower retention capacity for water and/or pollutants. According to Aller et
Table 5. Range and rating for topography (slope).

\begin{tabular}{lrr}
\hline Range (\%) & Rating & Index \\
\hline $0-2$ & 10 & 10 \\
$2-4$ & 9 & 9 \\
$10-12$ & 5 & 5 \\
$14-16$ & 3 & 3 \\
\hline
\end{tabular}

Weight: 1 (Ckakraborty, 2007)

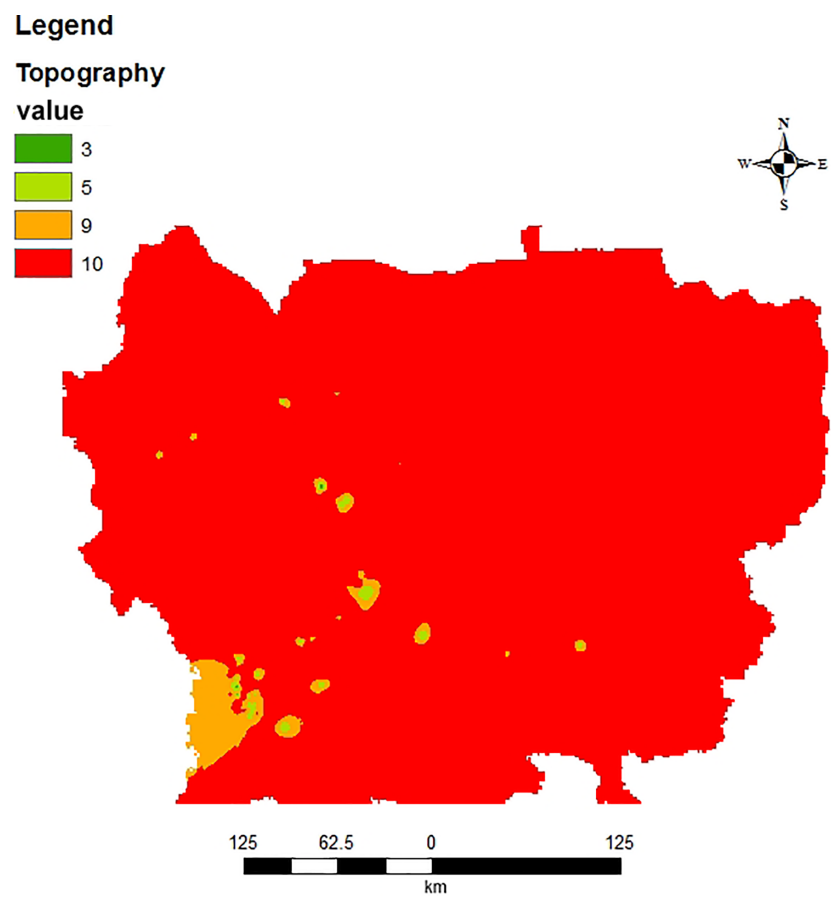

Figure 5. Slope distribution map.

al. (1987), topography has an effect on attenuation since it influences soil development.

Slope values extracted from a DEM of the region were reclassified and ranked on a scale (Table 5) of 1 to 10 to build the topography map (Fig. 5). This served as the basis of the multi-criteria analysis, in which other DRASTIC factors play a role.

\subsubsection{Impact of vadose zone}

The unsaturated or vadose zone is situated between the ground surface and groundwater table. It greatly impacts aquifer pollution potential due to its permeability, reactions, etc. (Corwin et al., 1997). Because the vadose zone is closely related to soil media and groundwater depth, we used the formula developed by Piscopo (2001) to estimate

$I_{r}=D_{r}+S_{r}$,

where $I$ is the impact of vadose zone, $D$ is water table depth, $S$ is soil media and $r$ is the rating. 
Table 6. Range and rating for vadose zone.

\begin{tabular}{lrr}
\hline Range & Rating & Index \\
\hline Clay and silt & 3 & 15 \\
Sandy clay & 4 & 20 \\
& 5 & 25 \\
Clay sand & 6 & 30 \\
Sand and gravel & 7 & 35 \\
& 8 & 40 \\
& 9 & 45 \\
& 10 & 50 \\
\hline
\end{tabular}

Weight: 5

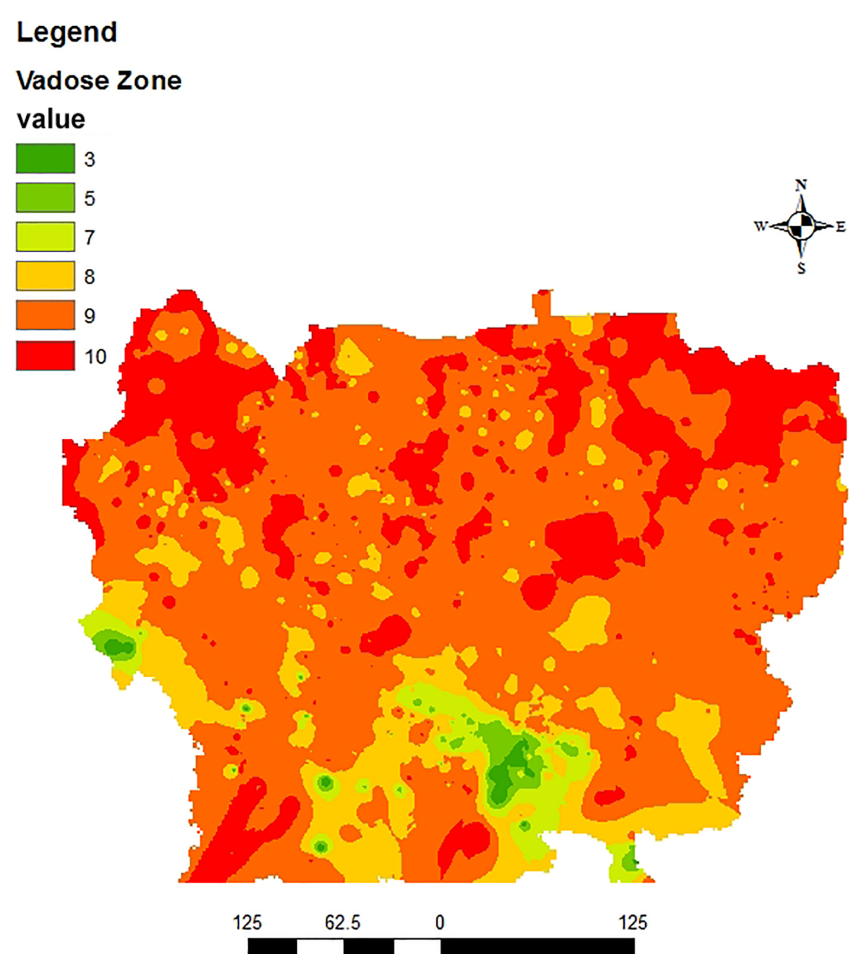

Figure 6. Vadose zone distribution map.

For groundwater depth we chose the following ratings: 5 for depths less than $10 \mathrm{~m}, 2$ for zones with depths between 10 and $30 \mathrm{~m}$ and 1 for regions where the water table static level is higher than $30 \mathrm{~m}$. Similarly we chose 5, 3 and 1 for, respectively, high-, medium- and low-permeability soils. Finally, we combined the two map layers to get the impact of vadose zone layer (Table 6 and Fig. 6).

\subsubsection{Hydraulic conductivity}

Hydraulic conductivity is the aquifer's capacity to transport contaminants (Ckakraborty, 2007). It plays a very important role in aquifer contamination potential because an aquifer with a high value of $\mathrm{C}$ is more easily contaminated and one with a low value of $\mathrm{C}$ is not (Fritch et al., 2000).
Table 7. Range and rating for hydraulic conductivity.

\begin{tabular}{lrr}
\hline Range (transmissivity) & Rating & Index \\
\hline$<10 \mathrm{~m}^{2}$ day $^{-1}$ & 1 & 4 \\
$10-20 \mathrm{~m}^{2}$ day $^{-1}$ & 2 & 8 \\
$20-30 \mathrm{~m}^{2}$ day $^{-1}$ & 3 & 12 \\
$30-100 \mathrm{~m}^{2}$ day $^{-1}$ & 4 & 16 \\
\hline
\end{tabular}

Weight: 3

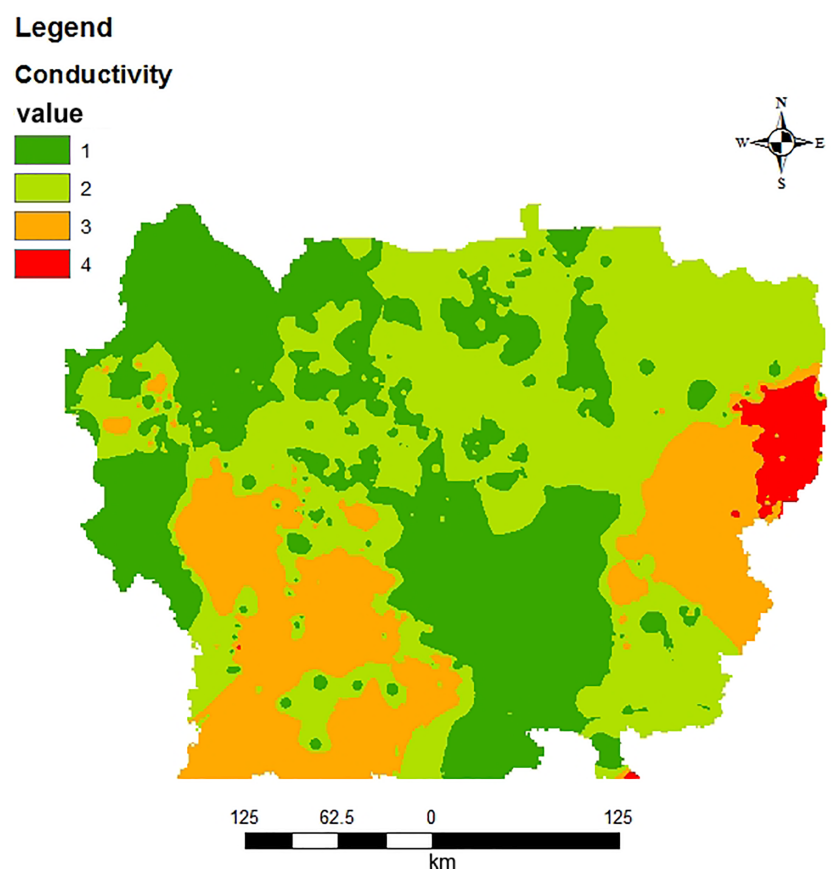

Figure 7. Hydraulic conductivity distribution map.

We used transmissivity values instead of hydraulic conductivity to build the map. We adopted the following rating system: for very high values $\left(>450 \mathrm{~m}^{2} \mathrm{day}^{-1}\right)$ we chose 10 ; for high values $\left(300-450 \mathrm{~m}^{2} \mathrm{day}^{-1}\right)$ we chose 8 ; for moderate values (100-300 $\left.\mathrm{m}^{2} \mathrm{day}^{-1}\right)$ we assigned 6 ; for moderately low values (30-100 $\mathrm{m}^{2} \mathrm{day}^{-1}$ ) we assigned 4; for low values $\left(20-30 \mathrm{~m}^{2} \mathrm{day}^{-1}\right)$ we chose 3 ; for very low values $\left(10-20 \mathrm{~m}^{2} \mathrm{day}^{-1}\right)$ we chose 2 ; and for extremely low values $\left(<10 \mathrm{~m}^{2}\right.$ day $\left.^{-1}\right)$ we assigned 1 as the rating value. The different values and distribution of hydraulic conductivity are shown in Table 7 and Fig. 7.

\subsection{Vulnerability assessment by the fuzzy method}

The DRASTIC method cannot consider the continuity passage from the highest polluted point to the lowest one, this property expresses the fuzzyness or the clouding effect of the aquifer to be polluted. So the fuzzy concept can be utilized to evaluate the groundwater pollution potential. For instance, we know that for vulnerability evaluation, when the water ta- 


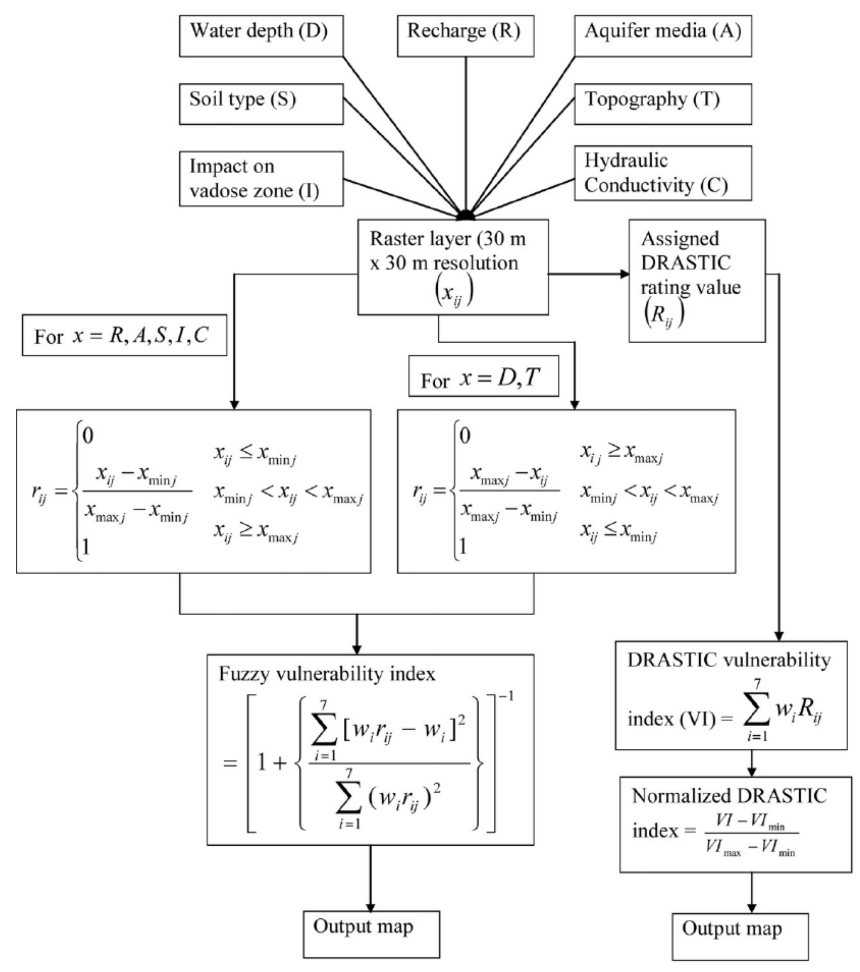

Figure 8. Flow chart of methodology adopted to develop the groundwater contamination potential map using DRASTIC and fuzzy pattern recognition models in the framework of GIS (source Pathak et al., 2009).

ble is shallow, the recharge rate is high, and if aquifer and soil materials are coarser, groundwater potential for pollution is higher. Also if the hydraulic conductivity, recharge rate and slope are low then the groundwater potential for pollution is low. The main concept using fuzzy logic is very simple: it expresses whether a statement is true or untrue as well as the degree of verity or wrongness for all the inputs (Pathak et al., 2009). A function of membership links all fuzzy sets. We coupled fuzzy optimized model with GIS to evaluate the vulnerability degree by converting the study area into a raster map and taking into account membership degrees in continuous passage from the highest polluted points to the lowest polluted points in hydrogeological settings.

\section{Optimized fuzzy model}

The fuzzy nature of groundwater vulnerability and groundwater vulnerability assessment can be considered as a particular property. For example, instead of numerical measurement of factors in the DRASTIC method, the fuzzy method describes continuously the links between those factors that affect groundwater.

The fuzziness can be expressed continuously by membership degrees from 0 to 1 . The following optimized model is used (Pathak et al., 2009).
Given a factor matrix,

$X=\left(x_{i j}\right)_{7 \cdot n}$,

where $x_{i j}$ denotes the value of tester $j$ in element $i$ $(i=1, \ldots, 7 ; j=1, \ldots)$ and $n$ is the overall number of sampling points.

We can classify DRASTIC factors into two main groups.

- Group 1: the increasing of parameter value increases groundwater vulnerability to pollution.

- Group 2: the increasing of parameter value decreases groundwater vulnerability to pollution.

This membership degree can be expressed mathematically for group 1 as

$r_{i j}\left\{\begin{array}{l}0 \text { if } x_{i j} \leq x_{\min j} \\ \frac{x_{i j}-x_{\min j}}{x_{\max j}-x_{\min j}} \\ 1 \text { if } x_{i j} \geq x_{\max j}\end{array}\right.$ if $x_{\min j} \geq x_{i j} \geq x_{\max j}$,

and for group 2 as

$r_{i j}\left\{\begin{array}{l}0 \text { if } x_{i j} \geq x_{\max } \\ \frac{x_{\max j}-x_{i j}}{x_{\max j}-x_{\min j}} \\ 1 \text { if } x_{i j} \leq x_{\min j}\end{array}\right.$ if $x_{\min j} \geq x_{i j} \geq x_{\max j}$,

where $r_{i j}$ is the degree of membership for the sample $j$ in factor $i, \min _{j}$ is the smallest value of element $i$ (i.e., 1 ) in the DRASTIC method and $\max _{j}$ is the maximum value of element $i$ (i.e., 10) in the DRASTIC method.

We can use Eqs. (4), (5) and (6) to get the following matrix for the connection of factors:

$\mathbf{R}=\left(r_{i j}\right)_{7 n}$,

with the following conditions for matrix $\mathbf{R}$ :

- if $r_{i j}=1$ then the tester $j$ has the highest potential for groundwater pollution according element $i$ only;

- if $r_{i j}=0$ then the tester $j$ has the lowest potential for groundwater pollution according the element $i$ only.

For example, when all element connection degrees to highest potential for groundwater pollution are 1, then

$R_{i j}=(1, \ldots, 1)$.

When all element connection degrees to lowest potential for groundwater pollution are 0 , then

$R_{i j}=(0, \ldots, 0)$.

So the membership degree of each or the parameters in sample $j$ is

$r_{j}=(r 1, \ldots, r 7) T$. 
Table 8. DRASTIC parameters.

\begin{tabular}{|c|c|c|c|c|}
\hline DRASTIC parameters & Range & Rating & Index & Weight \\
\hline \multirow[t]{7}{*}{ Groundwater depth (m) } & $0-1.5$ & 10 & 50 & 5 \\
\hline & $1.5-4.6$ & 9 & 45 & \\
\hline & $4.6-9.1$ & 7 & 35 & \\
\hline & $9.1-15.2$ & 5 & 25 & \\
\hline & $15.2-22.5$ & 3 & 15 & \\
\hline & $22.5-30$ & 2 & 10 & \\
\hline & $>30$ & 1 & 5 & \\
\hline \multirow[t]{5}{*}{ Net recharge $\left(\mathrm{mm}_{\text {year }}{ }^{-1}\right)$} & $0-50$ & 1 & & 4 \\
\hline & $50-100$ & 3 & & \\
\hline & $100-175$ & 6 & & \\
\hline & $175-225$ & 8 & & \\
\hline & $>225$ & 9 & & \\
\hline \multirow[t]{2}{*}{ Aquifer media } & Silty sand & 3 & 9 & 3 \\
\hline & Medium sand & 6 & 18 & \\
\hline \multirow[t]{4}{*}{ Soil media } & Gravel & 10 & 20 & 2 \\
\hline & Sandy loam & 6 & 12 & \\
\hline & Loam & 5 & 10 & \\
\hline & Clay loam & 3 & 6 & \\
\hline \multirow[t]{4}{*}{ Topography (\%) } & $0-2$ & 10 & 10 & 1 \\
\hline & $2-4$ & 9 & 9 & \\
\hline & $10-12$ & 5 & 5 & \\
\hline & $14-16$ & 3 & 3 & \\
\hline \multirow{13}{*}{$\begin{array}{l}\text { Impact of vadose zone } \\
\text { (soil + recharge) }\end{array}$} & $15-18$ & 10 & 50 & 5 \\
\hline & $13-15$ & & & \\
\hline & $10-13$ & & & \\
\hline & $8-10$ & & & \\
\hline & $6-8$ & & & \\
\hline & $4-6$ & & & \\
\hline & $<4$ & & & \\
\hline & & 9 & 45 & \\
\hline & & 8 & 40 & \\
\hline & & 7 & 35 & \\
\hline & & 5 & 25 & \\
\hline & & 3 & 15 & \\
\hline & & 1 & & \\
\hline \multirow{4}{*}{$\begin{array}{l}\text { Hydraulic conductivity } \\
\text { (transmissivity } \mathrm{m}^{2} \text { day }^{-1} \text { ) }\end{array}$} & $<10$ & 1 & 3 & 3 \\
\hline & $10-20$ & 2 & 6 & \\
\hline & $20-30$ & 3 & 9 & \\
\hline & $30-100$ & 4 & 12 & \\
\hline
\end{tabular}

In the DRASTIC system different parameters have different weights (from 5 to 1 ) in relation to vulnerability; these are normalized in the evaluation process to sum to 1 .

Let the weight vector be

$W=(w 1, \ldots, w 7) T$.

The distance from one given sample $j$ to the sample with the highest potential for groundwater pollution can be expressed as

$$
d_{1}=\sqrt[p]{\sum_{i=1}^{7}\left[w_{i}\left(r_{i j}-1\right)\right]^{p}} .
$$

The distance from one given sample $j$ to the sample with the lowest potential for groundwater pollution can be expressed as 
$d_{2}=\sqrt[p]{\sum_{i=1}^{7}\left(w_{i} r_{i j}\right)^{p}}$.

$p$ in Eqs. (11) and (12) is the distance factor; when $p=1$ the distances are called Hamming distances and when $p=2$ the distances are called Euclidean distances.

We used Euclidean distances in our study. We can see clearly that if $d_{1}=0$ then the given sample $j$ has the highest potential for groundwater pollution and when $d_{2}=0$ then the given sample $j$ has the lowest potential for groundwater pollution.

Let the membership degree of the highest potential for groundwater pollution be denoted by $u_{j}$ for a given sample $j$, so the membership degree of the lowest potential for groundwater pollution will be $\left(1-u_{j}\right)$ for the same given sample.

Membership can be regarded as weight in the fuzzy concept. So the following equations express more clearly continuous changes from a given sample $j$ to the highest potential for groundwater pollution as well as from the same given sample to the lowest potential for groundwater pollution. $D_{1}$ is the weighted distance to the highest potential for groundwater pollution.

$D_{1}=u_{j} \sqrt[p]{\sum_{i=1}^{7}\left[w_{i}\left(r_{i j}-1\right)\right]^{p}}$

$D_{2}$ is the weighted distance to the lowest potential for groundwater pollution.

$D_{2}=\left(u_{j}-1\right) \sqrt[p]{\sum_{i=1}^{7}\left(w_{i} r_{i j}\right)^{p}}$

To get an optimized solution for $u_{j}$ the objective function must be

$$
\begin{aligned}
\min \left\{F\left(u_{j}\right)\right. & \left.=\left(D_{1}^{2}+D_{2}^{2}\right)\right\}=u_{j}^{2}\left\{\sum_{i=1}^{7}\left[w_{i}\left(r_{i j}-1\right)\right]^{p}\right\}^{2 / p} \\
& +\left(1-u_{j}\right)^{2}\left\{\sum_{i=1}^{7}\left[w_{i} r_{i j}\right]^{p}\right\}^{2 p}
\end{aligned}
$$

After differentiating and solving Eq. (14), it becomes

$u_{j}=\left[1+\left\{\frac{\sum_{i=1}^{7}\left[w_{i\left(r_{i j}-1\right)}\right]^{p}}{\sum_{i=1}^{7}\left(w_{i} r_{i j}\right)^{p}}\right\}^{2 / p}\right]$.

Equation (16) is called the fuzzy optimization model; the higher the value of $u_{j}$, the higher the potential for groundwater vulnerability to pollution for a given tester $j$. This model

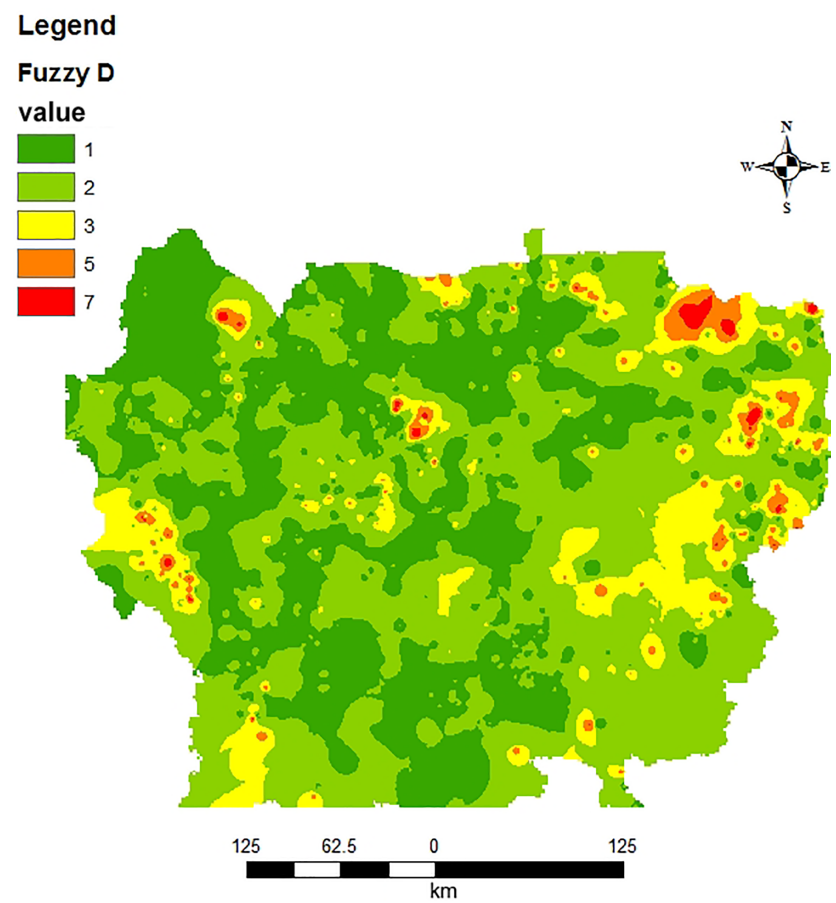

Figure 9. Fuzzy concept groundwater depth distribution map.

is joined to GIS and used to evaluate the pollution potential of groundwater. The diagram of procedures used to evaluate the map using DRASTIC and fuzzy methods in GIS is shown in Fig. 8.

\section{Results and discussion}

\subsection{Fuzzy and DRASTIC parameters}

Using memberships defined by fuzzy concept, groundwater table depth and topography maps were different from those of DRASTIC, but for the other five parameters the fuzzy optimized and DRASTIC maps were identical.

The groundwater table depth and topographic maps obtained by using fuzziness are shown in Fig. 9 and 10.

\subsection{Aquifer vulnerability maps}

The final DRASTIC potential index (DPI) was obtained by using Eq. (1) or (2) in ArcGIS 10.0 software on the seven individual map layers to produce the vulnerability map for the DRASTIC method. The DPI rating scores were from 72 to 141 and the greater the score was, the higher the aquifer vulnerability. We used natural break (jenks) classification to get three main classes, namely low vulnerability $(\mathrm{DPI}<110$ ), moderate vulnerability $(110<\mathrm{DPI}<120)$ and high vulnerability $(120<$ DPI $<141)$. Table 8 and Fig. 11 show DPI scores and distribution. 


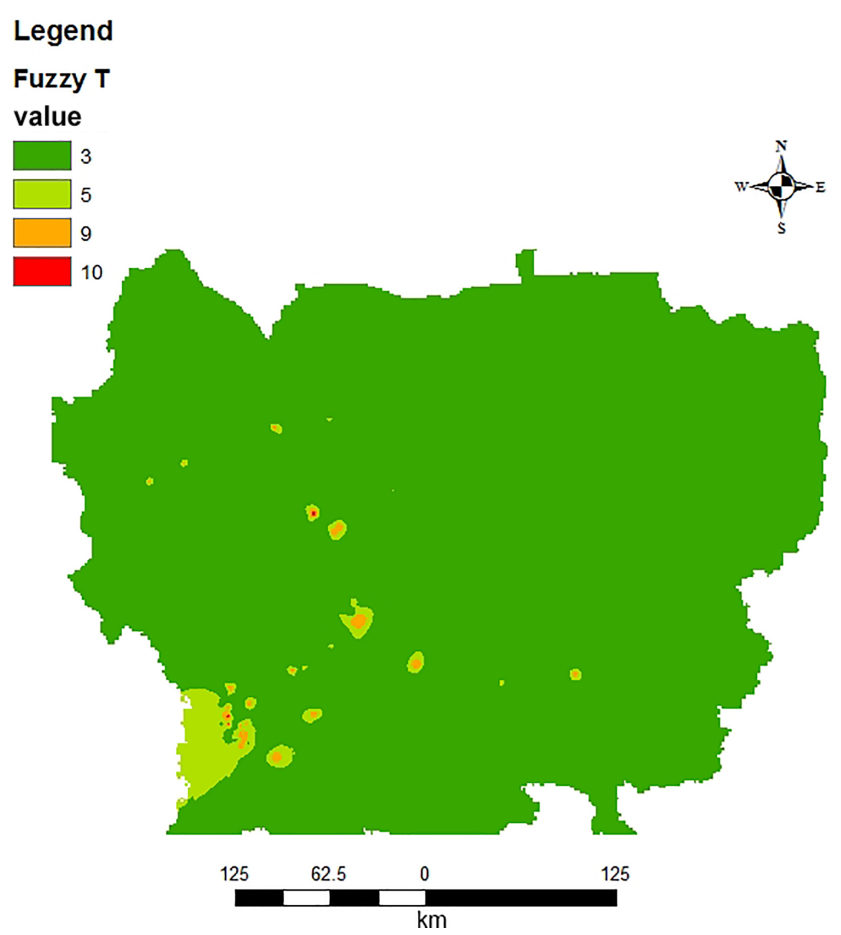

Figure 10. Fuzzy concept topography (or slope) distribution map.

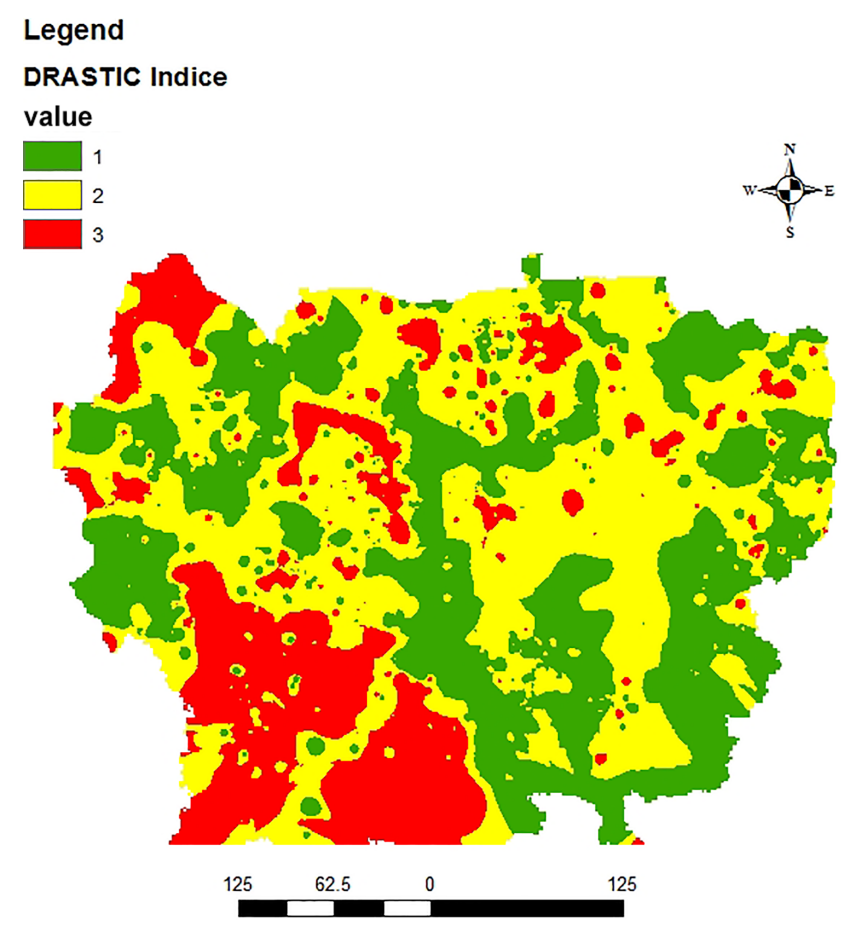

Figure 11. DRASTIC vulnerability map.

These values range from 72 to 141 and are classified into three distinct classes.

To facilitate and control scientific discussion, we used natural break (jenks) classification to get three vulnerability
Legend

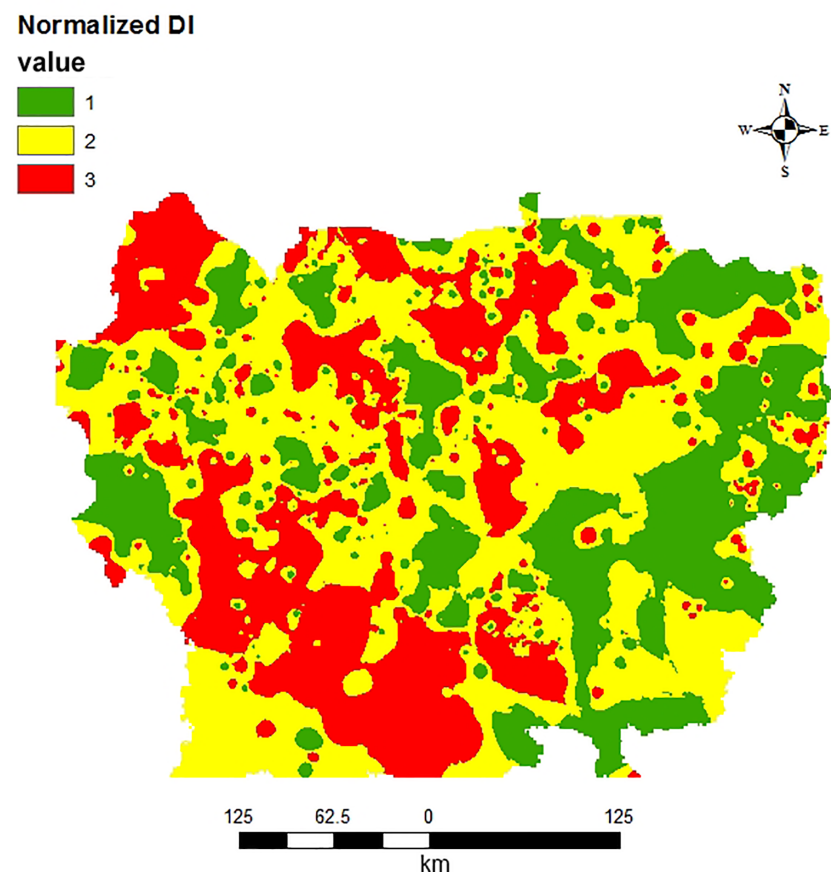

Figure 12. Normalized vulnerability map.

maps for both methods: the normalized DRASTIC method and fuzzy DRASTIC method.

Under these conditions Fig. 11 (DRASTIC method) shows that high-risk areas of Senegal basin in Mali are mainly situated in the northern and southwestern portion of the basin with $14.64 \%$ of total Senegal basin in Mali. The moderate risk areas, which cover $6.51 \%$ of the total basin, are somewhat disseminated and are mostly situated in the central and northern portion of the basin. Certain moderate risk areas are seen in the northeastern and western zones. All other portions of the Senegal basin in Mali are at low risk $(78.85 \%)$ and are found in the western and midwestern regions of the basin.

For the normalized vulnerability we found $21.68 \%$ for high vulnerability, $15.22 \%$ for moderate vulnerability and $63.32 \%$ for low vulnerability. The map is shown in Fig. 12.

For the fuzzy DRASTIC method we found $18.92 \%$ for the high-vulnerability zone, $8.94 \%$ for the moderatevulnerability zone and $72.11 \%$ for the low-vulnerability zone (Fig. 13).

The intrinsic method cannot show the influence of each individual feature on the final vulnerability index because the same weight and rating are assigned to a given parameter, making this method subjective. However, based on the relative significance (or importance) of a given parameter, the specific method uses weight and rating to get the final vulnerability index. So with the intrinsic method some parameters can be under- or overestimated, while with the specific method each parameter will have a specific (or actual) estimation. These are the main reasons why different zones 
Table 9. Statistical summary of the seven parameters for the two methods.

\begin{tabular}{lrr|rr|rr|rr|rr|rr|rr}
\hline & \multicolumn{2}{c|}{ D } & \multicolumn{2}{c|}{ R } & A & \multicolumn{2}{|c|}{ S } & T & I & \multicolumn{2}{c}{ C } \\
& $\mathrm{d}$ & $\mathrm{f}$ & $\mathrm{d}$ & $\mathrm{f}$ & $\mathrm{d}$ & $\mathrm{f}$ & $\mathrm{d}$ & $\mathrm{f}$ & $\mathrm{d}$ & $\mathrm{f}$ & $\mathrm{d}$ & $\mathrm{f}$ & $\mathrm{d}$ & $\mathrm{f}$ \\
\hline Min & 1 & 0.33 & 1 & 0 & 3 & 0.22 & 3 & 0.22 & 3 & 0 & 3 & 0.22 & 1 & 0 \\
Mean & 5.52 & 0.5 & 1.36 & 0.04 & 4.27 & 0.36 & 5.71 & 0.52 & 9.83 & 0.02 & 8.14 & 0.79 & 1.93 & 0.10 \\
Max & 7 & 1 & 3 & 0.22 & 6 & 0.55 & 10 & 1 & 10 & 0.77 & 10 & 1 & 4 & 0.33 \\
SD & 1.41 & 0.16 & 0.77 & 0.08 & 1.48 & 0.16 & 2.20 & 0.24 & 0.72 & 0.08 & 1.24 & 0.13 & 0.87 & 0.09 \\
\hline
\end{tabular}

Noted: $d$ indicates the DRASTIC method and $\mathrm{f}$ is the fuzzy method.

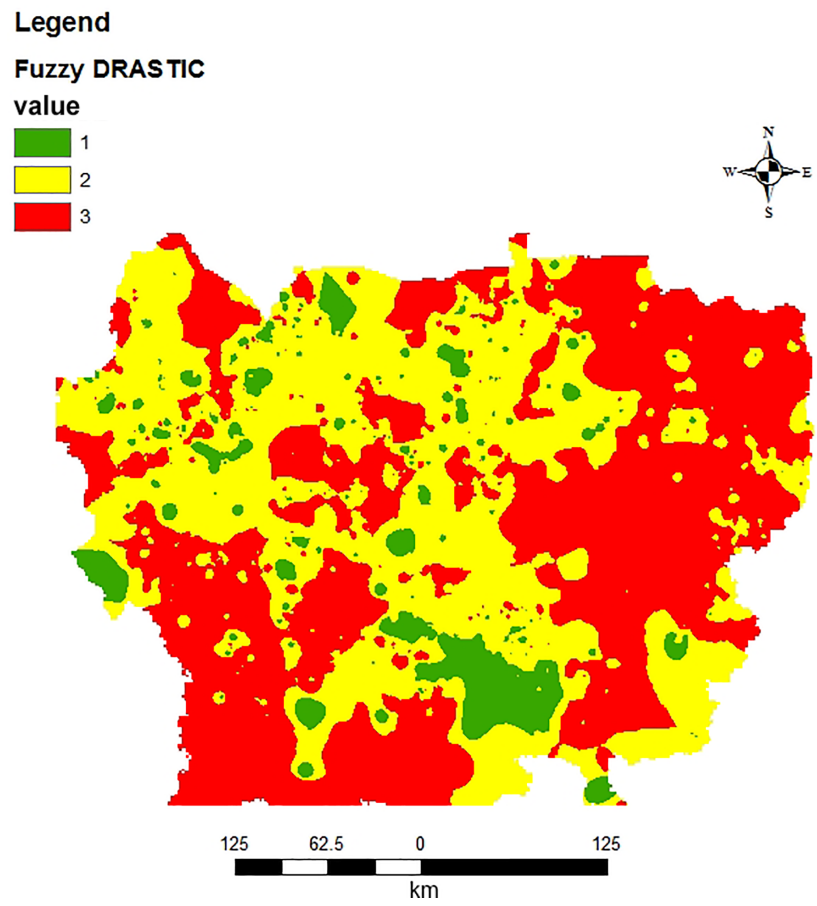

Figure 13. Fuzzy DRASTIC vulnerability map.

of the study had different vulnerability indexes according to each method.

However, Figs. 14-16 show that the coincidence ratio with high nitrate concentration for the fuzzy DRASTIC method is the highest $(81.13 \%)$, followed by the normalized DRASTIC method $(79.54 \%)$ and finally the DRASTIC method (77.31\%). This confirmed our assertion that the fuzzy method better assesses groundwater vulnerability to pollution than the simple DRASTIC method.

\subsection{Sensitivity analysis}

Seven hydrogeological parameters influence the transport of the contaminants to aquifers when using the DRASTIC approach. According to Rosen (1994), the high number of parameters is intended to decrease indecision associated with using the individual parameters on the results. However, several researchers (Merchant, 1994; Barber et al., 1994) opine

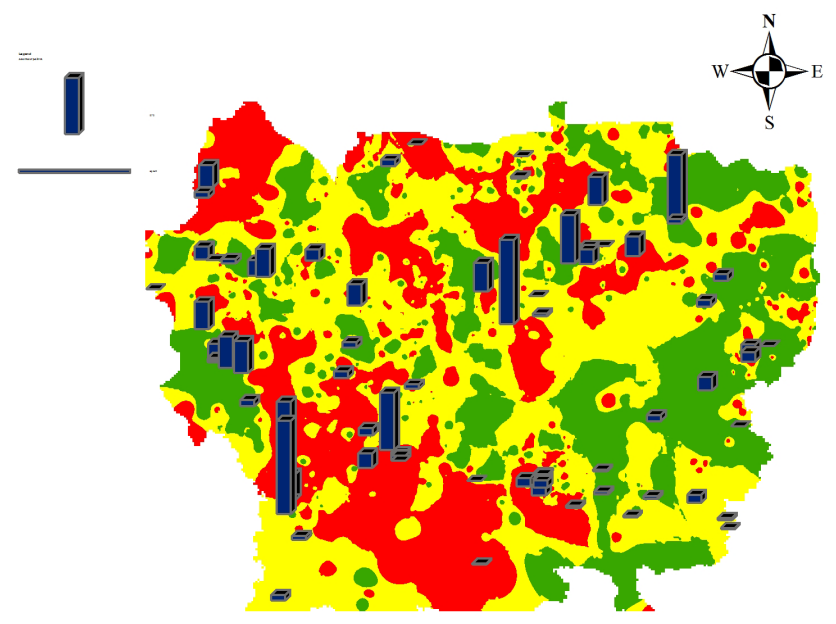

Figure 14. Nitrate distribution in the DRASTIC model.

that groundwater risk assessment is possible without using all seven parameters of the DRASTIC method. Other researchers (Napolitano and Fabbri, 1996) also criticized that the weights and the ratings for the seven parameters are assumed for DPI assessment and lead to uncertainties about the precision of the outcomes for pollution risk assessment. Many factors contribute to the output of the DRASTIC model (Rahman, 2008; Ckakraborty, 2007) including map units in each layer, the weights, the overlay operation type that is performed, the number of data layers, the error or doubt associated with each map unit, etc.

Sensitivity analysis was adopted to complement trial evidence for the DRASTIC method to perfect the uncertainty about model precision.

Two sensitivity analyses were then completed (Babiker et al., 2005; Lodwick et al., 1990): the map removal sensitivity test and the single parameter sensitivity analysis.

The map removal sensitivity test defines the sensitivity of risk map to each parameter by eliminating one (or more) 


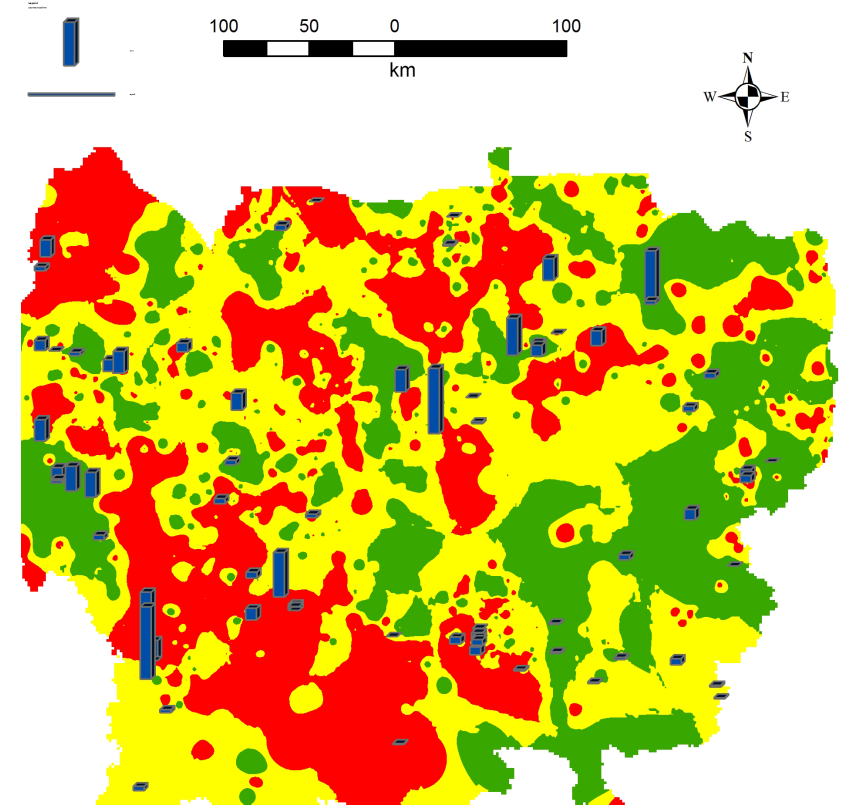

Figure 15. Nitrate distribution in the normalized model.
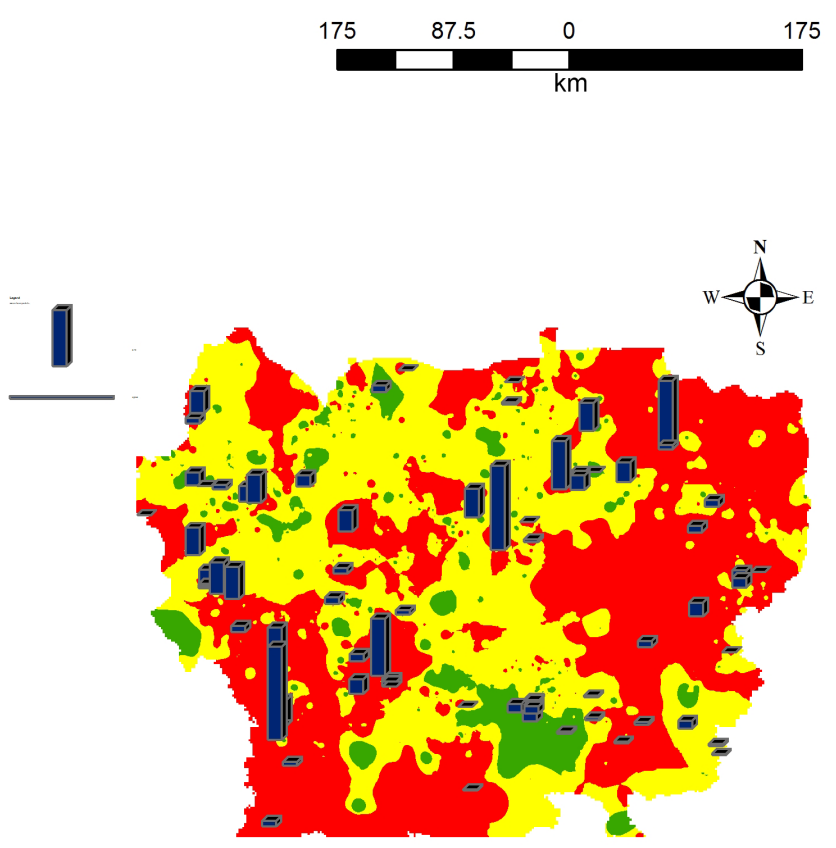

Figure 16. Nitrate distribution in the fuzzy model.

layer map and is applied using the following:

$S=\left(\frac{\left|\frac{V}{N}-\frac{V^{\prime}}{N}\right|}{V}\right) \cdot 100$.

$S$ is the sensitivity degree, $V$ is the unperturbed risk index using $N$ data layers and $V^{\prime}$ is the perturbed risk index with $N^{\prime}$ data layers. The real index $V$ is found by using all seven pa-
Table 10. Map removal sensitivity analysis (one parameter is removed at time).

\begin{tabular}{lrrrr}
\hline \multirow{2}{*}{ Parameters removed } & \multicolumn{4}{c}{ Variation index (\%) } \\
\cline { 2 - 5 } & Max & Mean & Min & SD \\
\hline D & 3.69 & 1.72 & 0 & 0.76 \\
R & 2.99 & 1.58 & 0 & 0.44 \\
A & 3.61 & 0.67 & 0 & 0.42 \\
S & 2.99 & 0.83 & 0 & 0.42 \\
T & 3.40 & 0.92 & 0.06 & 0.18 \\
I & 7.19 & 3.60 & 0 & 0.88 \\
C & 4.85 & 1.53 & 0.05 & 0.38 \\
\hline
\end{tabular}

Table 11. Map removal sensitivity analysis (one or more parameters are removed at time).

\begin{tabular}{lrrrr}
\hline \multirow{2}{*}{ Parameters removed } & \multicolumn{4}{c}{ Variation index (\%) } \\
\cline { 2 - 5 } & Max & Mean & Min & SD \\
\hline DASTIC & 2.99 & 1.58 & 0 & 0.44 \\
DASTI & 5.71 & 3.73 & 1.38 & 0.72 \\
DASI & 8.44 & 6.06 & 2.92 & 0.88 \\
DAI & 13.18 & 9.49 & 4.32 & 1.54 \\
DI & 22.04 & 15.76 & 1.94 & 2.72 \\
I & 43.18 & 21.63 & 0 & 5.33 \\
\hline
\end{tabular}

rameters while $V^{\prime}$ can have a smaller number of parameters for the calculation procedure.

To estimate the impact of individual parameter on the risk potential, we used the single parameter sensitivity test. During this test we compared the effective or actual weight of every individual factor with its hypothetical or allocated weight by using the following:

$W=\frac{P_{r} \cdot P_{w}}{V} \cdot 100$.

$W$ is the actual weight of the factor, $P_{r}$ is the rating, $P_{w}$ is the weight and $V$ is the risk index.

The statistical summary of all parameters is shown in Tables 8 and 9 . We noted that by using the DRASTIC method and Eq. (17) the highest vulnerability source is topography, which has a mean value of 9.83 . The second main parameter affecting the risk is the impact of the vadose zone (8.14), followed by soil media (5.71). After the vadose zone comes groundwater table depth, with a mean value of 5.52. The fifth and the sixth positions are occupied, respectively, by aquifer media (4.27) and hydraulic conductivity (1.93) for their contribution to groundwater pollution potential. Finally net recharge showed the least mean value for contribution to pollution risk in Senegal basin in Mali.

The effective weight, also called coefficient of variation (Eq. 18), shows that the main two parameters which impact the most DPI values are the unsaturated zone (or vadose zone) with $35.92 \%$ and groundwater table depth with 
Table 12. Single parameter sensitivity analysis (effective weights).

\begin{tabular}{lrr|rrr|c}
\hline Parameters & Theoretical & Theoretical & \multicolumn{3}{|c|}{ Effective weight (\%) } & SD \\
& weight & weight (\%) & Max & Mean & Min & \\
\hline D & 5 & $21.73(22)$ & 43.20 & 24.17 & 4.42 & 5.59 \\
R & 4 & $17.39(17)$ & 15.58 & 4.80 & 2.85 & 2.65 \\
A & 3 & $13.04(13)$ & 23.37 & 11.25 & 6.71 & 3.65 \\
S & 2 & $8.69(9)$ & 21.97 & 10,04 & 4.61 & 3.70 \\
T & 1 & $4.34(4)$ & 13.88 & 8.73 & 2.41 & 1.09 \\
I & 5 & $21.73(22)$ & 57.47 & 35.92 & 14.27 & 5.37 \\
C & 3 & $13.04(13)$ & 13.95 & 5.09 & 2.14 & 2.27 \\
\hline
\end{tabular}

$24.17 \%$. They are followed by aquifer media $(11.25 \%)$, soil media $(10.04 \%)$ and topography $(8.73 \%)$. Hydraulic conductivity and net recharge have relatively low variations with, respectively, 5.09 and $4.80 \%$. A low percentage means a small influence on variation of DPI across the basin.

Table 8 shows statistics and the correlation of the seven parameters used in both the DRASTIC and the fuzzy model. The average values of factors show that the vadose zone contributes the most DPI, with a mean value of $35.90 \%$ for the DRASTIC and 0.79 for fuzzy membership. Depth of the water table (24.17\% and 0.5$)$, aquifer media $(11.24 \%$ and 0.36$)$ and soil media ( $10.02 \%$ and 0.52 ) have a moderate contribution to the final vulnerability index. Topography $(8.72 \%$ and $0.02)$, hydraulic conductivity $(5.08 \%$ and 0.1$)$ and recharge ( $4.8 \%$ and 0.04 ) have a low contribution to the final vulnerability index.

\subsection{Map removal sensitivity analysis}

The first step of this test shows the change in DPI value when we remove only one map layer at a time. Tables 10 and 11 give the calculation results. Because the overall mean variation is not more that $1 \%$, the test does not describe very clearly DPI variation when removing only one map layer at a time; also, all mean values are almost the same. However, the maximum value of DPI variation was estimated when we removed the unsaturated zone parameter map with a relative mean variation of $3.60 \%$. This can be explained by its relatively high theoretical weight in the DRASTIC method and the nature of unsaturated zone material in the basin. Moderate variations were seen after removal of groundwater table depth $(1.72 \%)$, net recharge $(1.58 \%)$ and hydraulic conductivity $(1.53 \%)$. Only minor variations in mean values of DPI were noted (from 0.67 to $0.92 \%$ ) after removal of each of the other parameters from computation (Table 10).

The second step of the map removal sensitivity test shows the change in DPI value when we remove one or more map layers (or parameters) at a time from calculation. Based on the first step we removed parameters in the second step (Rahman, 2008; Babiker et al., 2005) by preferentially removing the parameters, which produced less variation on the final DPI value and then the next smaller, and so forth.
The smallest mean effective weight variation was seen after removal of net recharge $(4.80 \%)$ from the calculation. The more data layers we remove from calculation, the more the mean variation value increases because we keep the most effective parameters each time (Babiker et al., 2005).

\subsection{Single parameter sensitivity analysis (effective weight)}

The significance of each of the seven parameters has been shown in map removal sensitivity analysis. Now we need to understand whether the theoretical weight affected by each parameter in the DRASTIC model is its actual/real or effective weight after computation.

The actual weight represents the importance of the single factor compared with the other six factors and the weight given to it by the DRASTIC model (Rahman, 2008; Babiker et al., 2005). The single factor sensitivity test data can be seen in Table 12. The theoretical weight of both impact of unsaturated zone and groundwater static level is $21.73 \%$ but their actual or effective weights are, respectively, 35.92 and $24.17 \%$. Because their actual weight is higher than their hypothetical (assigned) weight we can say that they are the two most effective factors (or parameters) in this DPI calculation. The soil media parameter $(10.04 \%)$ and topography parameter $(8.73 \%)$ similarly indicate large effective weight in comparison to their theoretical weight (8.69 and $4.34 \%$, respectively). In contrast, the other three parameters presented less effective weight.

The importance of the four most effective parameters focuses on the need for precise data for building the model. The low recharge and hydraulic conductivity values in the Senegal basin contribute to reducing the significance of these parameters in the groundwater vulnerability assessment.

This study has demonstrated the closed and linear relationship between sensitivity analysis and fuzzy membership (Table 9). So instead of sensitivity analysis, we can also use fuzzy membership to find the main parameters which influence the groundwater potential vulnerability to pollution. 


\section{Conclusion}

Analyses were done with the purpose of observing the correlation between the intrinsic risk evaluation outcome and groundwater pollution in Senegal basin in Mali. DPI main values were low, moderate and high. In this study, a methodology was adopted to improve DPI calculation to produce a pollution potential map. This was achieved by including the homogeneous nature of vulnerability to pollution using DRASTIC factors in a vast area. In addition, field measured nitrate data were used to confirm the risk of pollution of the Senegal basin. Thus, we can say that passing from groundwater that is easiest to pollute to most difficult to pollute can be continuous. This proves in fact the fuzzy nature of risk to groundwater pollution. So, a combined GIS-built fuzzy design model produces a continuous risk assessment function, different levels of DRASTIC index, that is more accurate than the simple DRASTIC method. We compared simple DRASTIC, normalized DRASTIC and fuzzy DRASTIC outputs and it appeared that fuzzy index coincides the most with nitrate distribution in the study area. The outputs show that $18.92 \%$ of the study area's groundwater aquifer is at a high risk of pollution due to fuzzy DRASTIC while $14.64 \%$ of the study area's groundwater aquifer is at a high risk of pollution from the simple DRASTIC method.

From this outcome, it can be established that risk determined by the fuzzy method is more consistent than the DRASTIC method. For several aspects of the local and regional groundwater resource protection and management, the maps of groundwater risk to pollution established in this work are important tools in policy- and decision-making.

Data availability. Data can be accessed by emailing the corresponding author.

Competing interests. The authors declare that they have no conflict of interest.

Acknowledgements. The authors would like to acknowledge and thank the Government of Mali represented by the National Laboratory of Water (LNE), the National Directorate of Hydraulics, and the China University of Geosciences for their financial and technical support.

Edited by: Rosa Lasaponara

Reviewed by: Sidibe Aboubacar Modibo

and one anonymous referee

\section{References}

Afshar, A. I., Marino, M. A., Asce, H. M., Ebtehaj, M., and Moosa V. J.: Rule based fuzzy system for assessing groundwater vulnerability, J. Environ. Eng., 133, 532-540, 2007.

Alemi-Ardakani, M., Milani, A. S., Yannacopoulos, S., and Shokouhi, G.: On the effect of subjective, objective and combinative weighting in multiple criteria decision making: a case study on impact optimization of composites, Expert Syst. Appl., 46, 426438, 2016.

Aller, L., Truman, B., Rebecca, J. P., and Glen, H.: DRASTIC: a standardized system for evaluating groundwater pollution potential using hydrogeologic settings, CR-810715, U.S. Geological Survey, Environmental Protection Agency, 1987.

Anoh, K.: Évaluation de la vulnérabilité spécifique aux intrants agricoles des eaux souterraines de la région de Bonoua, Mémoire de DEA, Université de Cocody, Cocody, 68 pp., 2009.

Antonakos, A. K. and Lambrakis, N. L.: Development and testing of three hybrid methods for assessment of aquifer vulnerability to nitrates, based on the DRASTIC model, an example from NE Korinthia, Greece, J. Hydrol., 333, 288-304, 2007.

Anwar, P. and Rao, M.: Evaluation of groundwater potential of Musi River catchment using DRASTIC index model, in: Hydrology and watershed management, edited by: Venkateshwar, B. R., Ram, M. K., Sarala, C. S., and Raju, C., Proceedings of the international conference, 18-20, B.S. Publishers, Hyderabad (2003), 399-409, 2002.

Atkinson, S.: An examination of groundwater pollution potential through GIS modeling, ASPRS/ACSM, 1994.

Babiker, I. S., Mohammed, M., Hiyama, T., and Kato, K.: A GIS-based DRATIC model for assessing aquifer vulnerability in Kakamigahara Heights, Gifu Prefecture, central Japan, Sci. Total Environ., 345, 127-140, 2005.

Barber, C., Bates, L. E., Barron, R., and Allison, H.: Comparison of standardized and Region-specific methods assessment of the vulnerability of Groundwater to pollution: A case study in an Agricultural catchment, in: Proceedings of 25th IAH Congress water Down under, Melbourne, Australia, 1994.

Bezelgues, S., Des, G. E., Mardhel, V., and Dörfliger, N.: Cartographie de la vulnérabilité de Grand-Terre et de Marie-Galatie (Guadeloupe). Phase 1: Méthodologie de détermination de la Vulnérabilité, 2002.

Bojórquez-Tapia, L. A., Cruz-Bello, G. M., Luna-González, L., Juárez, L., and Ortiz-Pérez, M. A.: V-DRASTIC: using visualization to engage policymakers in groundwater vulnerability assessment, J. Hydrol., 373, 242-255, 2009.

Chandrashekhar, H., Adiga, S., Lakshminarayana, V., Jagdeesha, C. J., and Nataraju, C.: A case study using the model "DRASTIC" for assessment of groundwater pollution potential, in: Proceedings of the ISRS national symposium on remote sensing applications for natural resources, June 1999, 19-21, Bagalore, 1999.

Civita, M.: La Carte Della Vulnerabilità Degli Acquiferi All'inquiamento: Teoria e Pratica, edited by: PITAGORA, Bologna, 1994.

Ckakraborty, S.: Assessing aquifer vulnerability to arsenic pollution using DRASTIC and GIS of North Bengal Plain: A case study of English Bazar Block, Malda District, West Bengal, India, Vol.7, No.1, Springer, 2007. 
Corwin, D. L., Vaughan, P. J., and Loague, K.: Modeling nonpoint source pollutants in the vadose zone with GIS, Envir. Sci. Tech., 31, 2157-2175, 1997.

Denny, S. C., Allen, D. M., and Journea, Y. J.: DRASTIC-Fm: a modified vulnerability mapping method for structurally controlled aquifers in the southern Gulf 1slands, British Columbia, Canada, Hydrogeol. J., 15, 483-493, 2007.

Dhar, A.: Geostatistics-based design of regional groundwater monitoring framework, ISH J. Hydraul. Eng., 19, 80-87, 2013.

Dhar, A. and Patil, R. S.: Multiobjective design of groundwater monitoring network under epistemic uncertainty, Water Resour. Manage., 26, 1809-1825, 2012.

Dhar, A., Sahoo, S., Dey, S., and Sahoo, M.: Evaluation of recharge and groundwater dynamics of a shallow alluvial aquifer in Central Ganga Basin, Kanpur (India), Nat. Resour. Res., 23, 409422, 2014

Dhundi, R. P., Akira, H., Isao, A., and Luonan, C.: Groundwater vulnerability assessment in shallow aquifer of Kathmandu Valley using GIS-based DRASTIC model, Environmental Geology, 1569-1578, 2009.

Engel, B., Navulur, K., Cooper, B. S., and Hahn, L.: Estimating groundwater vulnerability to non point source pollution from nitrates and pesticides on a regional scale, Int. Assoc. Hydrol. Sci. Publi., 235, 521-526, 1996.

Fernando, A. L. P. and Luís, F. S. F.: The multivariate statistical structure of DRASTIC model, J. Hydrol., 476, 442-459, 2013.

Fritch, T. G., McKnight, C. L., Yelderman Jr., J. C., and Arnold, J. G.: An aquifer vulnerability assessment of the paluxy aquifer, central Texas, USA, using GIS and a modified DRASTIC approach, Environ. Manage., 25, 337-345, 2000

Hamza, M. H.: A GIS-based DRASTIC vulnerability and net recharge reassessment in an aquifer of a semi-arid region Metline-Ras Jebel-Raf Raf aquifer, Northern Tunisia, 2006.

Hamza, M. H., Added, A., Frances, A., and Rodriguez, R.: Validité de l'application des méthodes de vulnérabilité DRASTIC, SINTACS et SI à l'étude de la pollution par les nitrates dans la nappe phréatique de Metline-Ras Jebel-Raf Raf (Nord-Est Tunisien), Geoscience, 339, 493-505, 2007.

Hearne, G.: Vulnerability of the uppermost groundwater to contamination in the greater Denver Area, Colorado, USGS water resources investigation report 92-4143, 241 pp., 1992.

Heath, R. C.: Basic Groundwater Hydrology, US Geological Survey Water Supply paper 2220, US Department of the Interior, US Geological Survey, 1987.

Jha, M. K.: Vulnerability Study Of Pollution Upon Shallow Groundwater Using Drastic/GIS, 2005.

Jourda, J. P., Saley, M. B., Djagoua, E. V., Kouame, K. J., Biemi, J., and Razack, M.: Utilisation des données ETM+ de Landsat et d'un SIG pour l'évaluation du potentiel en eau souterraine dans le milieu fissure précambrien de la région de Korhogo (nord de la Côte d'Ivoire): approche par analyse multicritère et test de validation. Revue de Télédetection, 5, 339-357, 2006.

Jourda, J. P., Kouame, K. J., Adja, M. G., Deh, S. K., Anani, A. T., Effini, A. T., and Biemi, J.: Evaluation du degré de protection des eaux souterraines: vulnérabilité à la pollution de la nappe de Bonoua (Sud-Est de la Côte d'Ivoire) par la method DRASTIC, Actes de la Conférence Francophone, SIG 2007/ 10 au 11 Octobre 2007, Versailles-France, 11 pp., available at: www.esrifrance.fr/SIG2007/Cocody_Jourda.htm, 2007.
Kalinski, R.: Correlation between DRASTIC vulnerabilities and incidents of VOC contamination of municipal wells in Nebraska, Groundwater, 32, 31-34, 1994.

Kouame, K. J.: Contribution à la Gestion Intégrée des Ressources en Eaux (GIRE) du District d'Abidjan (Sud de la Côte d'Ivoire): Outils d'aide à la décision pour la prévention et la protection des eaux souterraines contre la pollution, Thèse de Doctorat, Université de Cocody, Cocody, 250 pp., 2007.

Leone, A., Ripa, M. N., Uricchio, V., Deak, J., and Vargay, Z.: Vulnerability and risk evaluation of agricultural nitrogen pollution for Hungary's main aquifer using DRASTIC and GLEAMS models, J. Environ. Manage., 90, 2969-2978, 2009.

Lodwik, W. A., Monson, W., and Svoboda, L.: Attribute error and sensitivity analysis of maps operation in geographical information systems-suitability analysis, Int. J. Geograph. Inf. Syst., 4, 413-428, 1990.

Luis, A. B. T., Gustavo, M. C. B., Laura, L. G., Lourdes, J., and Mario, A. O. P.: V-DRASTIC: Using visualization to engage policymakers in groundwater vulnerability assessment, J. Hydrol., 373, 242-255, 2009.

Lynch, S. D., Reynders, A. G., and Schulze, R. E.: Preparing input data for a national-scale groundwater vulnerability map of southern Africa, Document ESRI 94, 1994.

Madhumita, S., Satiprasad, S., Anirban, D., and Biswajeet, P.: Effectiveness evaluation of objective and subjective weighting methods for aquifer vulnerability assessment in urban context, J. Hydrol., 541, 1303-1315, 2016.

Merchant, J. W.: GIS-based groundwater Pollution hazard assessment a critical review of the DRASTIC model, Photogramm. Eng. Rem. S., 60, 1117-1127, 1994.

Mohamed, R. M.: Evaluation et cartographie de la vulnérabilité à la pollution de l'aquifère alluvionnaire de la plaine d'El Madher, Nord-Est algérien, selon la méthode DRASTIC, Sciences et changement planétaires, Sécheresse, 12, 95-101, 2001.

Murat, V., Paradis, D., Savard, M. M., Nastev, M., Bourque, E., Hamel, A., Lefebvre, R., and Martel, R.: Vulnérabilité à la nappe des aquifères fracturés du sud-ouest du Québec: Evaluation par les methods DRASTIC et GOD, Ressources Naturelles Canada, Commission Géologique, 2003.

Napolitano, P. and Fabbri, A. G.: Single parameter sensitivity analysis for aquifer vulnerability assessment using DRASTIC and SINTACS, in: Proceedings of the 2nd HydroGIS conference, IAHS Publication, Wallingford, 235, 559-566, 1996.

Neshat, A. and Pradhan, B.: An integrated DRASTIC model using frequency ratio and two new hybrid methods for groundwater vulnerability assessment, Nat. Hazards, 76, 543-563, $2015 \mathrm{a}$.

Neshat, A. and Pradhan, B.: Risk assessment of groundwater pollution with a new methodological framework: application of Dempster-Shafer theory and GIS, Nat. Hazards, 78, 1565-1585, 2015b.

Newton, J. T.: Case study of Transboundary Dispute Resolution: Organization for the Development of the Senegal River (OMVS), Transboundary Freshwater Dispute Database, Oregon State University, available at: http://www.transboundarywaters.orst.edu/ research/case_studies/OMVS_New.htm (last access: 26 February 2012), 2007.

Nobre, R. C. M., Filho, O. C. R., Mansur, W. J., Nobre, M. M. M., and Cosenza, C. A. N.: Groundwater vulnerability and risk 
mapping using GIS, modeling and a fuzzy logic tool, J. Contam. Hydrol., 94, 277-292, 2007.

O.M.V.S.: Le Journal N.8 Octobre, available at: http://www. portail-omvs.org/actualite/omvs-journal-ndeg-8-octobre, 2013.

Osborn, N. I., Eckenstein, E., and Koon, K. Q.: Vulnerability assessment of twelve major aquifer in Oklahoma. Oklahoma Water Resources Boards, Technical Report, 1998.

Pacheco, F. A. L. and Van der Weijden, C. H.: Delimitation of recharge areas in the Sordo river basin using oxygen isotopes, in: VIII Congresso Ibérico de Geoquímica - XVII Semana de Geoquímica. Escola Superior Agrária do Instituto Politécnico de Castelo Branco, Castelo Branco, 6 pp., 2011.

Pacheco, F. A. L. and Van der Weijden, C. H.: Integrating topography, hydrology and rock structure in weathering rate models of spring watersheds J. Hydrol., 428-429, 32-50, 2012.

Pacheco, F. A. L., Pires, L. M. G. R., Santos, R. M. B., and Fernandes, L. F. S.: Factor weighting in DRASTIC modeling, Sci. Total Environ., 505, 474-486, 2015.

Pathak, D. R., Hiratsuka, A., Awata, I., and Chen, L.: Groundwater vulnerability assessment in shallow aquifer of Kathmandu Valley using GIS based DRASTIC model, Environ. Geol., 57, 15691578, https://doi.org/10.1007/s00254-008-1432-8, 2009.

Piscopo, G.: Groundwater Vulnerability Map Explanatory Notes Castlereagh Catchment, Parramatta NSW, Australia NSW Department of Land and Water Conservation, 2001.

Rahman, A.: A GIS based DRASTIC model for assessing groundwater vulnerability in shallow aquifer in Aligarh, India, Appl. Geogr., 28, 32-53, 2008.

Rosen, L.: Study of the DRASTIC methodology with the emphasis on Swedish conditions, 37th conference of the International Association for Great Lakes Research and Estuaire Research Federation, Buffalo, p. 166, 1994.

Sahoo, S., Dhar, A., Kar, A., and Chakraborty, D.: Index-based groundwater vulnerability mapping using quantitative parameters, Environ. Earth Sci., 75, 1-13, 2016 a.
Sahoo, S., Dhar, A., and Kar, A.: Environmental vulnerability assessment using grey analytic hierarchy process based model, Environ. Impact Assess. Rev., 56, 145-154, 2016 b.

Saidi, S., Bouria, S., Dhiaa, H. B., and Anselmeb, B.: Assessment of groundwater risk using intrinsic vulnerability and hazard mapping: application to Souassi aquifer, Tunisian Sahel, Agric. Water Manage., 98, 1671-1682, 2011.

Samake, M., Zhonghua, T., Win, H., Innocent, M., and Kanyamanda, K.: Assessment of Groundwater Pollution Potential of the Datong Basin, Northern China, Journal of Sustainable Development, 3, 140-152, 2010.

Samake, M., Zhonghua, T., Win, H., Innocent, M., Kanyamanda, K., and Waheed, O. B.: Groundwater Vulnerability Assessment in Shallow Aquifer in Linfen Basin, Shanxi Province, China Using DRASTIC Model, Journal of Sustainable Development, 4, 53$71,2011$.

Sener, E., Sener, S., and Davraz, A.: Assessment of groundwater vulnerability based on a modified DRASTIC model, GIS and an analytic hierarchy process (AHP) method: the case of Egirdir Lake basin (Isparta, Turkey), Hydrogeol. J., 21, 701-714, 2013.

Sinha, M. K., Verma, M. K., Ahmad, I., Baier, K., Jha, R., and Azzam, R.: Assessment of groundwater vulnerability using modified DRASTIC model in Kharun Basin, Chhattisgarh, India, Arabian Journal of Geosciences, 9, 98-103, 2016.

Shirazi, S. M., Imran, H. M., Akib, S., Zulki, Y., and Harun, Z. B.: Groundwater vulnerability assessment in the Melaka State of Malaysia using DRASTIC and GIS techniques, Environmental Earth Sciences, 9, 1-22, 2013.

UNESCO: World Heritage related Category, available at: http:// whc.unesco.org/en/news/874, 2012.

Yu, C., Zhang, B., Yao, Y., Meng, F., and Zheng, C.: A field demonstration of entropyweighted fuzzy DRASTIC method for groundwater vulnerability assessment, Hydrol. Sci. J., 57, 1420-1432, 2012. 